\title{
Monitoring, Creeping, or Surveillance? A Synthesis of Online Social Information Seeking Concepts
}

\author{
Jessica R. Frampton \\ The Ohio State University, USA \\ frampton.22@osu.edu
}

\author{
Jesse Fox \\ The Ohio State University, USA \\ fox.775@osu.edu
}

\begin{abstract}
Affordances of Internet sites and Internet-based applications make personal information about romantic partners, friends, family members, and strangers easy to obtain. People use various techniques to find information about others, capitalizing on online affordances by using search engines to find relevant websites and databases; scouring the target's social media or social networking site presence; accessing information about the target via their links or network association with others on social media; or asking questions or crowdsourcing information through online channels. Researchers have coined an assortment of terms to describe online social information seeking behaviors, such as interpersonal electronic surveillance, social surveillance, monitoring, patient-targeted Googling, cybervetting, websleuthing, human flesh search, lateral surveillance, Facebook surveillance, and Facebook stalking. Although considerable research has examined these behaviors, there has been little effort to clarify the concepts themselves. As a result, the literature is currently full of inconsistent and overlapping conceptualizations. To synthesize these concepts for future research, this review examines 73 online social information seeking concepts extracted from 186 articles. Specifically, the concepts are reviewed in light of their scope; the information seeker or target of information seeking (e.g., romantic partners, parents, children, employees, criminals); motives for information seeking (e.g., uncertainty, threat, curiosity); and the intensity of the behavior. Recommendations are provided for future research, such as employing clear conceptualizations and incorporating affordances. Finally, we offer a decision tree that researchers can use to help select appropriate terms to use in their work moving forward.
\end{abstract}

Suggested citation: Frampton, J.R., \& Fox, J. (2021). Monitoring, creeping, or surveillance? A synthesis of online social information seeking concepts. Review of Communication Research, 9. http://doi.org/10.12840/ISSN.2255-4165.025

Keywords: communication technology, surveillance, cyberstalking, information seeking, social networking sites, monitoring, interpersonal electronic surveillance, social media, Internet

Editor: Giorgio P. De Marchis (Universidad Complutense de Madrid, Spain).

Reviewers: Andrew M. Ledbetter (Texas Christian University, USA); two reviewers prefer to stay anonymous.

Received: Nov. 11 th $^{\text {, }} 2019$ Open peer review: Nov. 2019 Accepted: Jul. 2020 Prepublished online: Jul. 2020 Published: Jan. 2021 


\section{Content}

INFORMATION SEEKING MODELS AND THEORIES …...................................

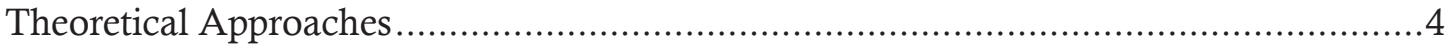

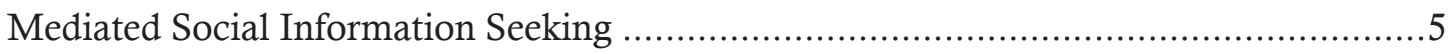

AFFORDANCES OF ONLINE COMMUNICATION TECHNOLOGIES ...................6

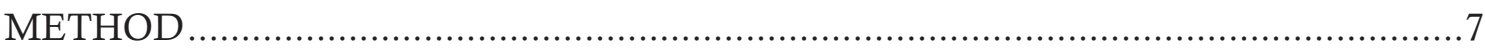

Identification of Online Social Information Seeking Concepts .................................. 7

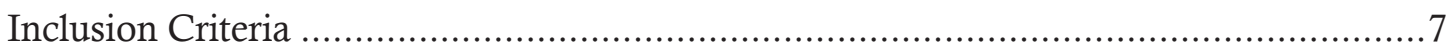

ANALYSIS OF THE CURRENT STATE OF THE LITERATURE ...........................

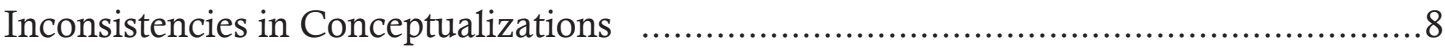

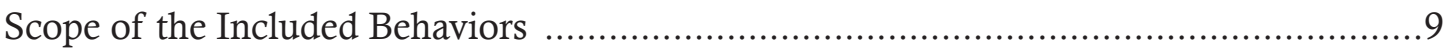

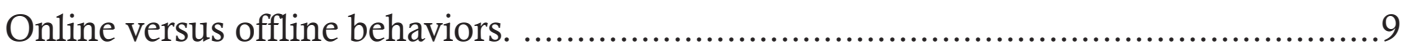

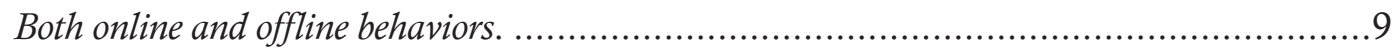

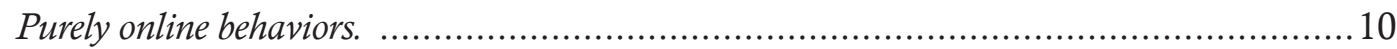

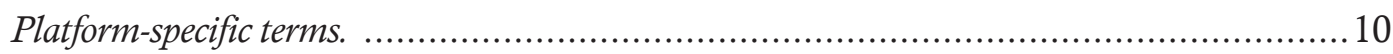

Terms exclusive to social information seeking versus more encompassing terms. ......11

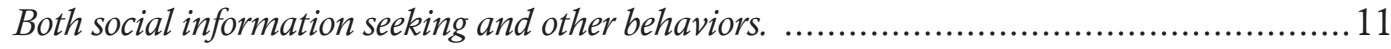

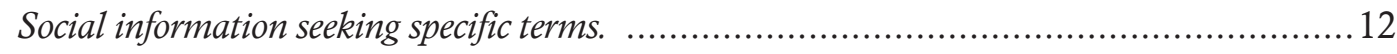

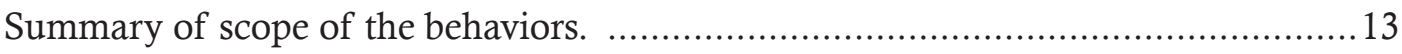

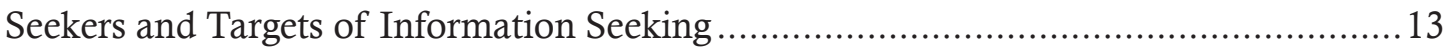

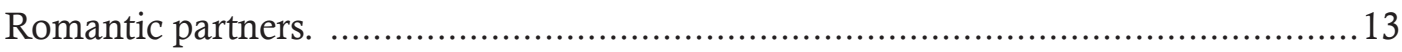

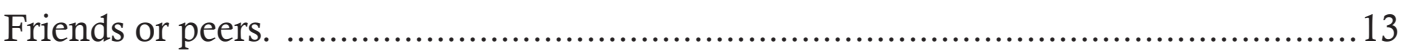

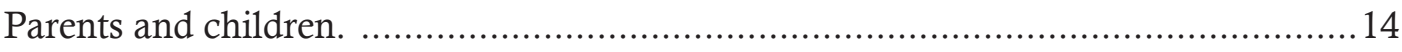

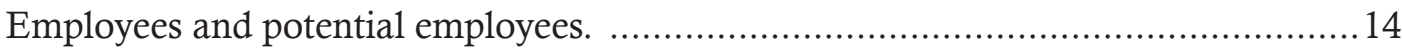

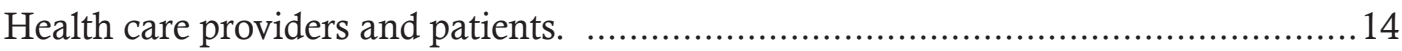

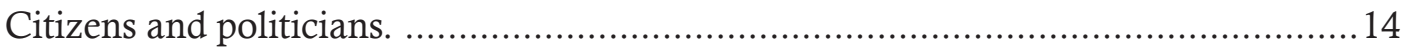

Online detectives, criminals, norm violators, or deceased individuals. .................... 14

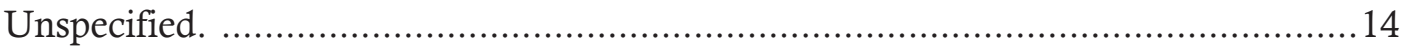

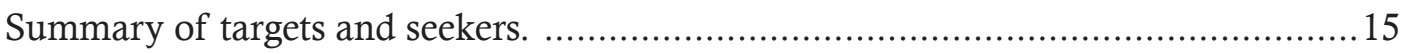

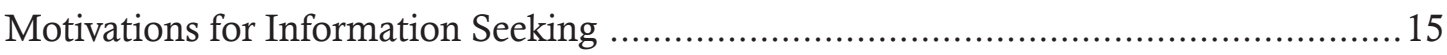

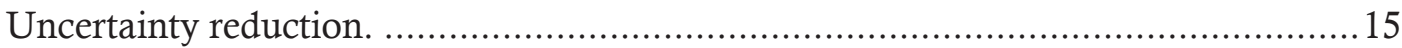

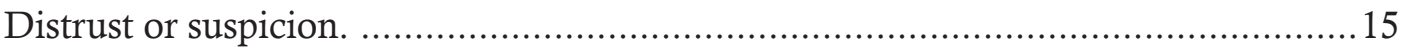

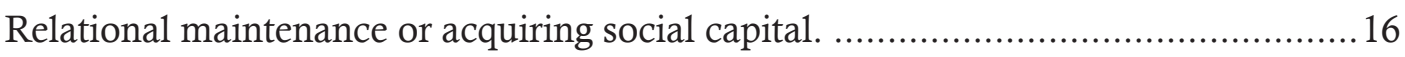

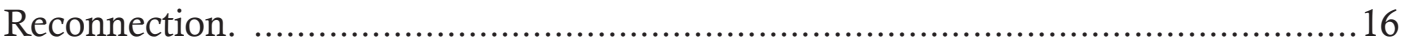

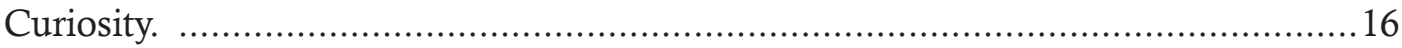

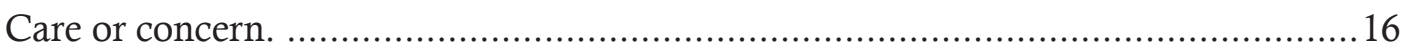

Resolve social injustice, identify missteps, or exact punishment. .......................... 16

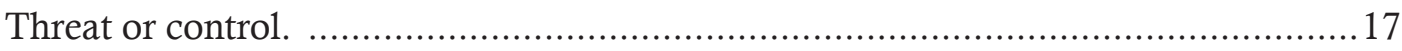

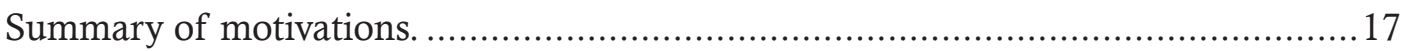

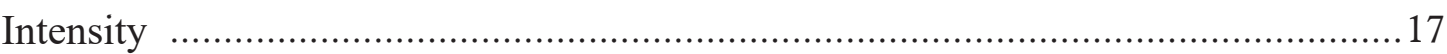

Time. …

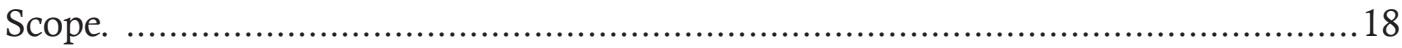

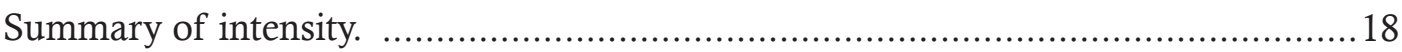

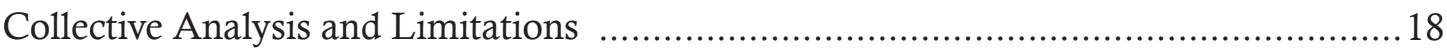


SUGGESTIONS FOR FUTURE RESEARCH …................................................. 19

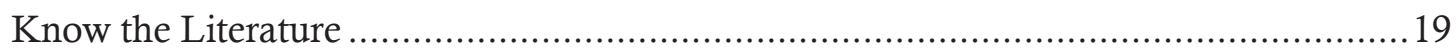

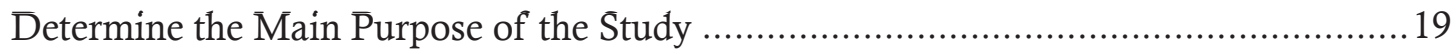

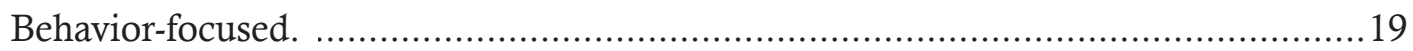

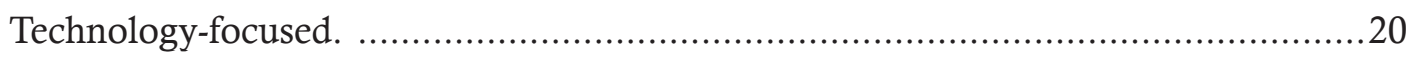

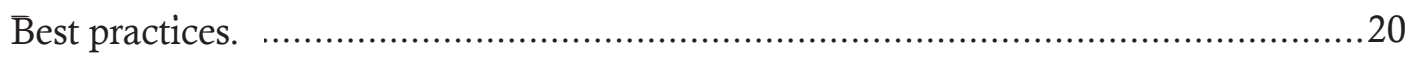

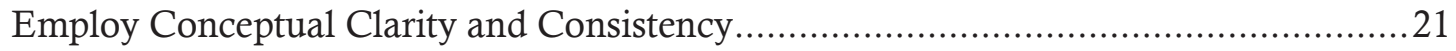

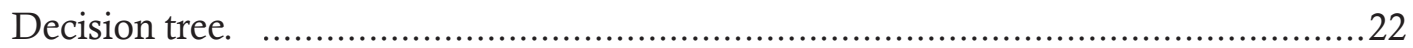

Figure 1. Decision tree for social information seeking terms....................................2 23

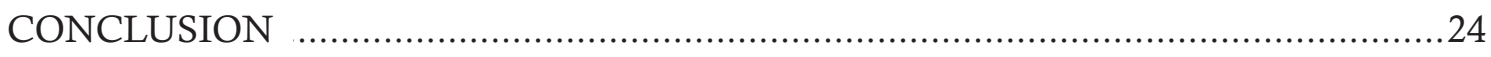

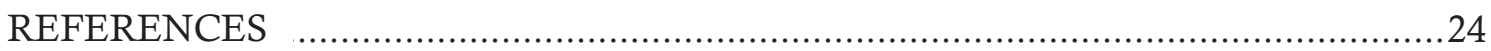

APPENDIX. List of online social information seeking concepts and articles that defined

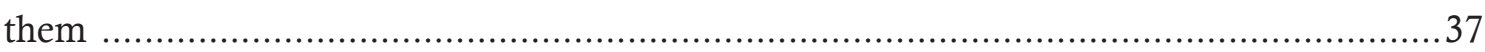

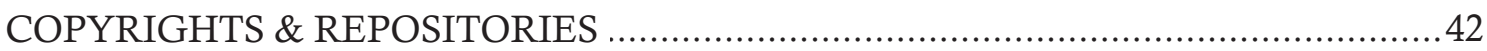

\section{Highlights}

- Affordances of communication technologies enable information seeking.

- A review of 186 articles that defined 73 online social information seeking terms revealed inconsistent conceptualizations in extant literature.

- Uses of the terms differ in their scope, target or seeker, motives for the behavior, and intensity.

- In the future, researchers should avoid the novelty fallacy, examine affordances, and employ conceptual clarity and consistency.

- Researchers can use the decision tree offered here to help select terms moving forward.

- State of the literature at October 1, 2019

Information seeking has been defined as "the gathering of information from all manner of sources through all manners of intentional acts-be it question asking, observing others, or searching formal information systems like libraries or databases" (Hogan \& Brashers, 2009, p. 50). Both people and organizations engage in information seeking regarding a wide range of topics such as health (Rains, 2018), news (Knobloch, Carpentier, \& Zillmann, 2003), and risk (Griffin, Neuwirth, Dunwoody, \& Giese, 2004). However, social information seeking is different from other types of information seeking in that it involves an individual or informal group of individuals purposively looking for personal data about a human target other than themselves. For example, a person may engage in information seeking about a potential romantic partner to determine if the potential partner would be a good match (Andrejevic, 2005) or to figure out if the person is already in a relationship (Fox,
Warber, \& Makstaller, 2013).

Social information seeking is thus distinguished by four characteristics. First, the seeker is an individual or informal group of individuals. This definition excludes automated searching initiated by a technology rather than a human (e.g., facial recognition scans) as well as mass surveillance efforts by governments, corporations, and other organizations. Second, although sending messages may be a part of the search process, from the perspective of the traditional sender-messagechannel-receiver model of communication, the primary aim is to receive information rather than send it. This aim distinguishes information seeking from information sharing or disclosure. Third, information seeking consists of deliberate, purposive behaviors meant to satisfy a goal, though the goal may vary depending on the context of the information seeking (Hogan \& Brashers, 2009). Brashers (2001) conceptualized information seeking as a subset of information acquisition, 
which also includes obtaining information that is not actively sought. People may glean information through incidental exposure even though they are not actively seeking it. Finally, the target of social information seeking is a specific person rather than a collective of people or a topic. Thus, mass surveillance is also excluded by this criterion. Additionally, in many cases, a seeker will ask another person for information about a topic that may involve personal experience. For example, as a father, Robby may message his Facebook friend Grace to ask how she mentored her son Bryan about career paths (see Crowley \& High, 2018). Robby is not seeking information about Bryan specifically, but rather about the topic of mentoring his own children. In these situations, the seeker is not interested in the person per $s e$, and therefore does not meet our definition for social information seeking.

There are a variety of terms that refer to social information seeking, such as surveillance (Guerrero \& Afifi, 1998) and parental monitoring (Law, Shapka, \& Olson, 2010). However, as communication technologies enabled novel ways of seeking information that go beyond what is possible in purely offline contexts, scholars in a variety of fields (e.g., psychology, communication, information science) began examining online social information seeking behaviors. We define online social information seeking as a human or informal group of humans purposively looking for personal data about a human target other than themselves via the Internet or Internet-based applications. Over the years, many terms have been used to describe online social information seeking. For example, interpersonal electronic surveillance (Tokunaga, 2011) and Facebook stalking (Meenagh, 2015; Trottier, 2012) are but two of the terms used to describe online social information seeking. Although extensive research has investigated these types of behaviors, there has been little effort to clarify the concepts themselves. As a result, the literature is full of inconsistent conceptualizations and applications of the terms.

This review seeks to clarify the breadth and use of online social information seeking concepts. Within this synthesis, we first explain the theoretical importance of social information seeking. We then describe how affordances enable online social information seeking, including information seeking that occurs via social media and that which occurs on broader search engines such as Google. Next, we identify articles that defined online social information seeking concepts, point out inconsistencies in conceptualizations in the literature, and analyze how the various terms are similar or different. Finally, we close with some recommendations for future research and a decision tree for researchers to use when selecting terms moving forward.

\section{Information Seeking Models and Theories}

Information seeking has been a common topic in mass communication research, particularly given the purpose of many mass media is to convey information to a broad audience. The uses and gratifications perspective has framed information seeking as one of the primary motivations for media use (Katz, Blumler, \& Gurevitch, 1974; Rubin, 2009). Similarly, information seeking and exchange has been a primary driver of interpersonal communication research and theorizing about relationship development. Several relational models and theories discuss the role of information seeking and sharing to increase intimacy, escalate the relationship, or reduce unwanted uncertainty about the relationship (e.g., Altman \& Taylor, 1973; Baxter, 1988; Knobloch \& Solomon, 2002). Uncertainty reduction theory (Berger \& Calabrese, 1975), the theory of motivated information management (Afifi \& Weiner, 2004; Afifi \& Morse, 2009), and uncertainty management theory (Brashers, 2001, Hogan \& Brashers, 2009) in particular predict when and how people will engage in various types of information seeking behaviors. These three theories were originally developed in offline, face-to-face contexts, but they have since been applied to online communication.

\section{Theoretical Approaches}

Berger (1979) and Berger and Bradac (1982) extended the original explication of uncertainty reduction theory to describe several different types of information seeking behaviors. They suggested that people can engage in passive information seeking strategies, which "are those in which we as observers gain knowledge of other persons by observing them without them knowing that we are observing them" (Berger \& Bradac, 1982, p. 18). When discussing passive information seeking, Berger and Bradac argued that people prefer to observe information targets in informal social contexts, such as talking to others at a party. Presumably, people can gather the most authentic information about others when they see how they interact in a situation with few role constraints. However, Berger (1979) noted it may be difficult to 
be unobtrusive in such face-to-face social situations. People can also engage in active information seeking behaviors, which consist of both observing the target's reactions to manipulations of the interaction environment and asking others for information about the target (Berger \& Bradac, 1982). Lastly, people can engage in interactive information seeking behaviors, which are strategies wherein the information seeker directly communicates with the information target.

Berger and Bradac's (1982) passive, active, and interactive information seeking strategies have been extensively examined in later research. For example, Baxter and Wilmot (1984) suggested that their 14 secret tests (i.e., strategies people use to acquire information about the state of their relationship) can be generally thought of as types of passive, active, and interactive information seeking strategies. People wondering about the state of their relationship may directly question their partner (an interactive strategy), ask the partner's friends about the partner's perception of the relationship (an active strategy), or give the partner a chance to be unfaithful and observe what the partner does (a passive strategy; Baxter \& Wilmot, 1984).

Although Berger and Bradac (1982) expanded the original version of uncertainty reduction theory (Berger \& Calabrese, 1975), they still assumed that people desire to reduce uncertainty when motivated to do so. In the theory, uncertainty is seen as the driver behind information seeking in its various forms. Uncertainty management theory (Brashers, 2001; Hogan \& Brashers, 2009) moved beyond this view of uncertainty as inherently negative and suggested there are a wide variety of information management strategies people use to either increase, decrease, or maintain uncertainty levels. Thus, information seeking is only one of many possible information management strategies. Additionally, Hogan and Brashers (2009) suggested that information handling (i.e., what people do with acquired information) and information use (i.e., the process of incorporating information into cognitions and behaviors) are related to, but different from, information seeking. Though uncertainty management theory was initially developed in the context of illness, specifically HIV/ AIDS (Brashers et al., 2000), the theory has since been used to explain communication in a variety of other contexts such as long-distance relationships (Maguire, 2007).

The theory of motivated information management (Afifi \& Weiner, 2004) likewise suggests that information seeking is only one of several information management options. It posits that people may engage in passive, active, or interac- tive information seeking during the decision phase of the information management process depending on the discrepancy between their current level of uncertainty and their desired level of uncertainty.

\section{Mediated Social Information Seeking}

The literatures on information seeking in interpersonal and mass communication contexts have intersected throughout the history of communication research. Several scholars examined how individuals sought information through media to gratify specific interpersonal needs. For instance, Atkin (1972) argued that people used mass media to educate themselves about current events and other socially relevant topics in anticipation of interpersonal discussion. Studies have also shown that people seek media to learn about interpersonal interactions and relationships (e.g., Bond, Hefner, \& Drogos, 2003; Wood, Senn, Desmarais, Park, \& Verberg, 2002). Other studies have investigated how mass media have been used for social information seeking. Most of this research has focused on garnering knowledge about a specific public figure, such as a political candidate, musician, athlete, or other celebrity (e.g., Becker \& Doolittle, 1975; Clarke, 1973; Miller \& MacKuen, 1979).

Widespread adoption of the Internet presented new opportunities for social information seeking through a variety of sources in a variety of contexts. Early computer-mediated communication (CMC) work examined how individuals interacting through channels like text chat sought information about and disclosed information to their interaction partner (e.g., Tidwell \& Walther, 2002). Notably, researchers explored how people employed Berger and Bradac's (1982) uncertainty reduction strategies in the context of the Internet in addition to suggesting another term for information seeking. In particular, Ramirez, Walther, Burgoon, and Sunnafrank (2002) added extractive information seeking to Berger and Bradac's typology. Extractive information seeking strategies "focus on the use of non-human sources of information such as online searches. These strategies include searching for information from sources beyond just the SNS, including photographs, blogs, comments, or reviews posted on unrelated venues (e.g., Pinterest or Yelp)" (Ramirez et al., 2016, p. 495). However, it is important to note that much of the content used for online social information seeking originates from human, rather than non-human, sources (e.g., SNS posts); the human communication is just delivered through 
a mediated channel.

Other researchers began to investigate how people used a variety of $\mathrm{CMC}$ channels to obtain information about another person, including email, instant messaging, and Internet searches (e.g., Westerman, Van Der Heide, Klein, $\&$ Walther, 2008). Over time, masspersonal communication channels that blended features of both interpersonal and mass communication (O'Sullivan \& Carr, 2018), such as social networking sites that allow posting to a large audience, became a major source for social information seeking (Walther \& Ramirez, 2009). Across channels, the characteristics or properties of communication technology enabled various information seeking behaviors.

\section{Affordances of Online Communication Technologies}

Affordances are the properties of an object that enable the user to take specific actions (Gibson, 1979). Although designers typically create and embed affordances within objects, users' perceptions of these affordances may vary considerably. How users perceive these affordances influences their behavior (Fox \& McEwan, 2017). For example, a user might think it is easy to delete a social media post and that it will disappear without any record, not understanding that other users could have captured a screenshot of the post before it was deleted.

Affordances are crucial for studying and understanding communication channels because they allow us to identify meaningful similarities and differences in the ways people interact with them and through them. These similarities and differences are also crucial because they help determine whether research findings generated in one channel generalize to another. Given that social information seeking theories originated before the Internet was widely available, it is important to consider how the variations in affordances have influenced this behavior.

Researchers have identified a number of affordances that facilitate social information seeking. The affordance of accessibility is the ease by which information can be shared or obtained (Tokunaga, 2011). The Internet grants unprecedented access to a multitude of sources from around the world, including organizational websites, government databases, news archives, and user-generated content, such as personal websites and social media profiles. Compared to offline settings, the Internet makes information gathering easy: with just a click of a mouse or the swipe of a finger, a vast array of information about romantic partners, peers, and even strangers can be obtained 24 hours a day. Because mobile devices and apps are portable and often within reach, they also promote greater accessibility.

Compared to obtaining information directly through interpersonal sources, information seeking online may also seem more anonymous (Fox \& McEwan, 2017). Seekers may not be comfortable asking a target or an acquaintance about a sensitive topic such as the target's criminal history or romantic past, whereas they may feel the Internet allows them to investigate more covertly without anyone being able to identify them.

Because online information is digital, it is easily generated, copied, and shared, making it more replicable compared to other channels. Social media in particular make socially relevant information widely, and often publicly, visible; even with the use of privacy settings, information is often more easily obtained than through offline channels (Tokunaga, 2011; Treem \& Leonardi, 2013). Additionally, information may be more persistent, remaining online years after it was first posted (Tokunaga, 2011; Treem \& Leonardi, 2013). Both visibility and persistence enhance searchability: names or other details can be tracked down through the use of powerful search engines like Google or site-specific search functionality, such as hashtags or the use of filters. Because many online sites accommodate multimodality, seekers may uncover a variety of media when searching, including text, audio, photographs, and video (Tokunaga, 2011). Due to variations in bandwidth, or the number of cues transmitted, information obtained through different media may be interpreted differently (Fox \& McEwan, 2017). People tend to view face-to-face communication as richer, and thus more authentic, than many forms of CMC (Fox \& McEwan, 2017).

Other affordances may also lead seekers to question the authenticity of online information. In a face-to-face conversation, disclosure is synchronous, meaning it is typically generated, sent, and received in an instant; online, there is a lag that affords editability (Walther, 1996). Across channels like texting, online chat, or social media posts, users can generate a message, revise it before sending, or decide to delete it instead of sending it. These affordances of asynchronicity and editability may make seekers more wary of information that they encounter online, especially if it was shared by the target (Walther \& Parks, 2002).

Social networking sites (SNSs) are a type of social media 
that are especially useful for social information seeking. SNSs like Facebook, Twitter, and Instagram enable users to build profiles and share information about themselves. A defining affordance of SNSs is network association, wherein users visibly link to other users (Fox \& McEwan, 2017). In this way, users can be tracked down not only through their own profiles, but through their links to other ties; sometimes these indirect linkages increase the visibility of a target's profile or posts. For example, sites like Facebook offer privacy settings wherein content is viewable only by direct ties (friends), by indirect ties (friends-of-friends) or by all Facebook users. Even if a target has a more private profile and only links to a few close ties, those ties may have an extensive audience that reveals information about the target by sharing content the target posts or by referring to, tagging, or otherwise including the target in their own posts. In this way, users often have limited control over who can see their content or, due to the scalable nature of digital material, how widely it is shared (boyd, 2011). Although information can be spread in many ways (e.g., gossiping face-to-face or over the phone; being featured in news media), SNSs allow information to be transmitted much faster and can reach a far larger audience.

In sum, information seekers capitalize on various affordances of online communication technology to learn personal information about others. As we have clarified, the affordances described above are not unique to online contexts, but many are greater or more easily achieved online. Although researchers have made progress in understanding the affordances of technology that allow for online social information seeking, there has been limited development of online social information seeking concepts themselves. Thus, the purpose of this review is to identify and address online social information seeking concepts.

\section{Method}

\section{Identification of Online Social Information Seeking Concepts}

To identify concepts for this synthesis, we employed several methods for finding articles. First, we searched the EBSCO Communication and Mass Media Complete and PsycINFO databases for articles written in English. We started with searching for known terms elaborated in the existing social information seeking literature ("surveillance," "monitoring," "information seeking," "stalking,", and "investigation") and combining them with indicators of computer-mediated processes ("online," "cyber," "electronic," "digital," "computer," "virtual," "social media," "Facebook," "web", "Internet," "site," and "social network"), using variations and Boolean operators as needed (appending * to expand searches; using AND or OR). We read the titles and abstracts of all articles and identified them as potentially relevant if they mentioned individuals seeking information about other people in some capacity. Next, we read each of the potentially relevant papers and determined whether an online social information seeking concept was explicitly defined. We also examined cited references in these articles to identify relevant papers that may have been missed by these initial search terms in these databases. We employed reverse lookup techniques to identify articles that had cited the articles we identified as well. As we engaged in this iterative process, we added new search terms based on the concepts we identified.

\section{Inclusion Criteria}

To be included in this synthesis, an article must have conceptually defined an online social information seeking term in some way. Consistent with our definition outlined above, an online social information seeking concept was defined as a term that describes a human or informal group of humans purposively looking for personal data about a human target other than themselves (e.g., romantic partners, friends, strangers) via the Internet or Internet-based applications. Although there is extensive work on mass surveillance by government agencies and automated monitoring for advertising purposes (e.g., Rider, 2018; Stoycheff, Wibowo, Liu, \& Xu, 2017; Woods, 2018), such work does not meet our outlined criteria for social information seeking and thus is beyond the scope of this review. If articles used concepts discussed in this synthesis, but they did not define the concepts in social information seeking terms, they were excluded. For example, an article that defined cyberstalking as repeatedly sending unwanted, sexual electronic messages to a target or assuming the target's identity to post on the Internet was not included because it did not incorporate seeking personal information about the target in the definition (e.g., Alexy, Burgess, Baker, \& Smoyak, 2005) although other papers using this term did (e.g., Finn, 2004). Likewise, articles that used concepts discussed in this synthesis (e.g., 
monitoring, surveillance) but did not provide a clear conceptual definition were not included (e.g., Rueda, Lindsay, \& Williams, 2014; Tong, 2013). A total of 186 relevant papers were identified that defined 73 online social information seeking concepts. All terms, along with every article that conceptually defined each term, can be found in the appendix.

\section{Analysis of the Current State of the Literature}

We read and recorded the definitions of the 73 online social information seeking concepts provided in each of the 186 articles. While reading through the definitions, we made notes about any identifying features of the concepts (i.e., we engaged in initial coding; Saldaña, 2013). From these preliminary jottings, similarities and differences emerged based on the most common use of the terms. Specifically, online social information seeking concepts differed in terms of their scope of included behaviors, the information target and seeker, the motivation behind the behavior, and the intensity of the behavior.

Furthermore, we also recorded the academic field each article came from based on the authors' affiliations so that we could explore whether there were consistent differences in terminology based on fields of study. There were few noticeable differences in the use of the various concepts or in the definitions of the various concepts between disciplines. Terms such as cyberstalking, social browsing, and interpersonal electronic surveillance were used and defined in similar ways by scholars across fields such as communication, education, information systems and management, sociology, and psychology. The one exception was the use of the term patient-targeted Googling. This concept was found almost exclusively in articles originating from psychotherapy (e.g., Ashby et al., 2015; Clinton et al., 2010; Eichenberg \& Herzberg, 2016). Other concepts, such as scandal mining (Trottier, 2018), appeared in only one article. Still others were used primarily by one set of authors (e.g., adolescent dating violence and abuse; Stonard, Bowen, Lawrence \& Price, 2014; Stonard, Bowen, Walker, \& Price, 2017). It is difficult to determine if these particular concepts are specific to a certain field or author without more instances of use.

\section{Inconsistencies in Conceptualizations}

At present, the distinction between many online social information seeking terms is muddled at best. For instance, Chia (2019) argued that cyber vigilantism is equivalent to websleuthing. Likewise, partner monitoring, creeping, and surveillance appear to be conflated in extant literature (e.g., Muise, Christofides, \& Desmarais, 2014); yet, other scholars suggest that there are differences between terms such as surveillance and monitoring (Botan, 1996; Fuchs, 2011). Marcum and colleagues (Marcum \& Higgins, 2019; Marcum, Higgins, \& Poff, 2016) have argued that cyberstalking and digital or cyber dating abuse are often used interchangeably, and Brem et al. (2019) noted that terms such as cyberstalking, electronic surveillance, and cyber abuse "describe potentially synonymous constructs" (p. 416). However, others consider cyberstalking as only a subset of digital or cyber dating abuse (e.g., Van Ouystel, Ponnet, \& Walrave, 2018). At the same time, Tokunaga and Aune (2017) noted that "confusion surrounds the term cyberstalking because it is used aside colloquial phrases such as Facebook stalking or friend stalking" (p. 1453).

Moreover, Wise, Alhabash, and Park (2010) argued that "extractive strategies are analogous to social searching, while passive strategies are analogous to social browsing" (p. 556), and Marshall, Bajanyan, Di Castro, and Lee (2013) stated that interpersonal electronic surveillance, social surveillance, social searching, and Facebook surveillance all "describe the covert use of technology to observe other people's online and offline activities" (pp. 1-2). Park, Shin, and Ju (2015) used the term social surveillance, arguing that the concept of interpersonal electronic surveillance "is a concept similar to social surveillance in this study" and that the concept of social searching "has a similar meaning to that of social surveillance" (p. 602). However, the conceptual distinction between the three terms was not clarified.

Conceptual definitions of online social information seeking terms also vary between articles. For example, the general consensus is that when a social media user engages in creeping on another person's profile, they typically do not leave any traces of their visit (Fox, Warber, \& Makstaller, 2013; Muise et al., 2014; Standlee, 2019). Yet, Wittkower (2016) defined creeping as "a vice consisting in an inappropriate excess of interaction" (p. 7), and instead used the term lurking to refer to observing interactions on SNSs without commenting. Similarly, Tokunaga (2011) stated that interpersonal electronic surveillance can "only occur once for it 
to be considered an instance of surveillance" (p. 707); yet, later Fox and Tokunaga (2015) defined interpersonal electronic surveillance as "persistent monitoring of a partner's online activity" (p. 491). Others also defined interpersonal electronic surveillance as "frequent scouring of a person's online presence" (Marcum, Higgins, \& Nicholson, 2018, p. 718). As another example, human flesh search has been referred to as "the activity of tracking down and publishing on the Internet the personal information of those whom according to Chinese Internet users have engaged in corrupt practices and immoral behavior" (Ong, 2012, p. 130). But, others have used the term to refer to almost any collaborative online search effort, such as when Chen and Sharma (2011) defined it as "a joint effort by thousands of online participants to retrieve information in a collaborative manner" (p. 50).

Sometimes, definitions even vary within the same article. For example, Omaggio, Baker, and Conway (2018) first stated patient-targeted Googling (PTG) occurs when providers "gather information about patients using a search engine such as Google" (p. 481). Later, they broadened the definition: "PTG is a term for searching online for patient information using search engines (e.g., Google) and social media sites" (p. 482). Perhaps this difference can be explained by the fact that some PTG scholars "use the words 'Googling' or 'to Google' to refer to the practice of online searching, whether or not that practice involves the Google search engine" (Clinton et al., 2010, p. 103). However, PTG is not the only term defined inconsistently within the same article. Berkelaar (2017a) first defined cybervetting as "employers' use of online information from social media and search engines to evaluate job candidates" (p. 1115). Later, another definition of cybervetting was provided that included a wider range of purposes for information seeking about employees: "covertly gathering online information from informal, noninstitutional online sources via social media and search engines to help decide whom to recruit, hire, promote, or fire" (p. 1116). Thus, the term cybervetting is not always restricted to hiring decisions. Indeed, other articles often refer to cybervetting as a form of information seeking about both prospective and current employees (e.g., Ashuri \& Bar-Ilan, 2017; Berkelaar, 2017b; Berkelaar \& Buzzanell, 2014).

Given the varying uses of online social information seeking terms, these concepts need to be refined for future research. In the following sections, we present four key distinctions that emerged based on the most common usage of the terms in extant literature. Specifically, conceptual definitions of online social information seeking terms often varied regarding the scope of behaviors covered by the terms, the target of information seeking or the seeker, the motivations for the behavior, and the intensity of the behavior. After discussing these trends, we provide recommendations for conceptualizing online social information seeking behaviors in future research.

\section{Scope of the Included Behaviors}

The concepts identified in this synthesis range from broad terms that include both online and offline information seeking behaviors to specific terms describing behaviors performed on a certain platform (e.g., Facebook stalking). This synthesis also includes terms that refer to a wide range of behaviors that go beyond information seeking, whereas other concepts refer exclusively to social information seeking.

Online versus offline behaviors. One key distinction between various terms is whether they describe behaviors that occur solely online or describe behaviors that can occur offline as well. Of those that occur entirely online, some terms refer to platform-specific behaviors.

Both online and offline behaviors. Based on current definitions, broad terms that encompass both online and offline information seeking behaviors include surveillance, snooping, post-relationship contact and tracking, adolescent dating violence and abuse, interactive (social) information seeking, passive (social) information seeking, active (social) information seeking, obsessive relational intrusion, rubbernecking, and perhaps the broadest of them all, the generic information seeking. One of the most widely used terms, surveillance, refers to intentionally viewing information about others or using technical means to extract personal data (Marx, 2004; Sheldon \& Bryant, 2016). Lee, Ho, and Lwin (2017) described how SNSs democratized interpersonal surveillance and promoted a culture of surveillance wherein people can easily retrieve information about their peers.

Furthermore, some researchers compared monitoring to spying and recognized that monitoring could happen outside of the Internet (e.g., Samp \& Palevitz, 2014; Stewart et al., 2014). However, in the majority of articles examined for this synthesis, monitoring was defined in relation to watching a partner online. For example, Stewart et al. (2014) defined monitoring as "examining a partner's online interactions for the purpose of seeing what the partner is communicating 
and with whom s/he is connecting" (p. 15). However, Stewart et al. later clarified that online monitoring is different than "other forms of monitoring" (p. 22). Likewise, rubbernecking refers to an interest in "accessing what individuals would not typically witness in their lives" (Baruh \& Cemalcilar, 2015, p. 507). It often occurs when people "view or become involved in the events surrounding a death or traumatic accident of a person they do not personally know" and "might include reading a deceased's obituary, viewing newspaper articles describing fatal accidents, or observing online message boards that discuss the deceased" (DeGroot, 2014, p. 80). Furthermore, Wang et al. (2010) argued that most human flesh search "episodes involve strong offline elements, in the form of either information acquisition through offline channels or other types of offline activism" (p. 46). However, other scholars use the term to exclusively refer to online searches for information (e.g., Cheong \& Gong, 2010; Gao, 2016).

A few other concepts were used in relation to seeking information about a romantic partner either online or offline. Derby, Knox, and Easterling (2012) defined snooping as "investigating (without the partner's knowledge) a romantic partner's private communication" (p. 20). The authors suggested snooping includes checking a partner's internet history and email in addition to searching their room, desk, or clothes. Thus, the concept includes both offline and online information seeking behaviors. Post-relationship contact and tracking is a similar concept that involves investigating a former partner's whereabouts, new partner, or activities both online and offline (Lee \& O'Sullivan, 2014). Moreover, both adolescent dating violence and abuse and obsessive relational intrusion involve negative behaviors that occur either electronically or in person (Chaulk \& Jones, 2011; Stonard et al., 2014).

Finally, the general term information seeking has been conceptualized as "the pursuit of desired information about a target" (Ramirez, Walther, Burgoon, \& Sunnafrank, 2002, p. 217). Ramirez et al. (2002) extended three types of information seeking behavior originally elaborated in uncertainty reduction theory (Berger \& Calabrese, 1975) to online environments as well: interactive (social) information seeking, passive (social) information seeking, and active (social) information seeking.

Purely online behaviors. Ramirez and colleagues (2002, 2016) suggested extractive information seeking strategies occur solely online. Similarly, doing homework occurs when people "conduct social media investigations of potential friends and use that data to determine if a relationship continues" (Standlee, 2019, p. 770). Other terms used to describe solely online behaviors include online surveillance (e.g., Tokunaga, 2016), monitoring of attractive peers on social networking sites (MAP-SNS; Vandenbosch \& Eggermont, 2016), and patienttargeted Googling. Despite the platform-specific jargon of this latter term, its conceptualization includes "a healthcare professional using a social networking site (SNS) or publicly available search engine to find patient information online" (Chester, Walthert, Gallagher, Anderson, \& Stitely, 2017, p. 1).

Social browsing (e.g., Joinson, 2008; Wise et al., 2010), passive usage (Verduyn et al., 2015, 2017), social information consumption (Krasnova, Widjaja, Buzmann, Wenninger, \& Benbasat, 2015), and lurking (e.g., Pempek, Yermolayeva, \& Calvert, 2009; Undewood \& Ehrenreich, 2017) are all conceptually similar terms used to describe seeking non-specific information about others online. Additionally, cybervetting, and the similar terms social media assessment and social recruiting, are often defined as online behaviors (Berkelaar, 2017a, 2017b; Berkelaar, Scacco, \& Birdsell, 2015; El Ouirdi, E1 Ouirdi, Segers, \& Pais, 2016; Roth, Bobko, Van Iddekinge, $\&$ Thatcher, 2016). For example, cybervetting occurs "when information seekers (employers) gather information about targets (workers) from informal, non-institutional, online sources to inform personnel selection decisions" (Berkelaar, 2014, p. 480).

Digilantism and the conceptually similar cyber vigilantism or crowdsourced vigilantism likewise involve online activities (Chia, 2019; Schwarz \& Richey, 2019), as does websleuthing (Myles, Benoit-Barné, \& Millerand, 2018). Lastly, some scholars conceptualized cyberstalking as an entirely online phenomenon (e.g., Adam, 2002; Kircaburun, Jonasonb, \& Griffiths, 2018; Tavani, \& Grodzinsky, 2002; Tokunaga \& Aune, 2017). However, others say it can involve other forms of technology, not just devices capable of accessing the Internet (e.g., Reyns, Henson, \& Fisher, 2011; Smoker \& March, 2017). Finally, voyeurism was defined as "the use of social media use to find social information about others" (Quinn \& Papacharissi, 2018, p. 54). On the other hand, the related term mediated voyeurism is not always conceptualized as occurring solely via social media (e.g., Bumgarner, 2007).

Platform-specific terms. A small number of concepts are subsets of more general terms, but they are specific to certain SNSs. For example, Instagram browsing describes a type of 
social browsing that occurs exclusively on Instagram (Yang, 2016). Likewise, Facebook surveillance is a type of surveillance that occurs only on Facebook (Marshall et al., 2013). Mediated lurking (i.e., "monitoring, scrutiny, and prolonged use of Facebook to try to discover information about another"; Child \& Starcher, 2016, p. 484) is also a term defined exclusively in reference to information seeking via Facebook thus far.

Trottier (2012) suggested that creeping is a milder form of Facebook stalking, although Fox et al.'s (2013) participants made a slightly different distinction, suggesting creeping was a more common practice that involved a wider range of targets, whereas Facebook stalking was a more persistent, in-depth pursuit usually of a single target (e.g., a desired romantic partner). It should be noted that Facebook stalking is not always conceptualized as a subset of cyberstalking, which seems counter-intuitive. Tokunaga and Aune (2017) stated that Facebook stalking is a term used in public discourse to refer "to surreptitious online information-seeking behaviors," whereas "cyberstalking involves the repeated pursuit of a targeted individual over the internet" (p. 1453). When developing a measure for Facebook stalking, Lyndon et al. (2011) included both harmful behaviors that would be considered cyberstalking by most definitions (e.g., creating a false Facebook profile of an ex-partner to cause them problems) and more neutral information seeking behaviors not necessarily associated with harm (e.g., looking through an ex-partner's photos). Indeed, other researchers have suggested that Facebook stalking is a colloquial term referring to frequent visits to a target's page regardless of the motivation for information seeking (Fox et al., 2013). Other Facebook-specific terms include Facebook investigating (Stiff, 2019), Facebook partner monitoring (Darvell, Walsh, \& White, 2011), passive Facebook use (Frison \& Eggermont, 2016; Shaw, Timpano, Tran, \& Joormann, 2016), and Facebook tracking (Stiff, 2019).

Terms exclusive to social information seeking versus more encompassing terms. Some terms we identified are broad, umbrella terms that include not only social information seeking behaviors, but other actions as well. However, many of the terms are restricted solely to social information seeking.

Both social information seeking and other behaviors. Terms such as digital or cyber dating abuse, adolescent dating violence and abuse, and electronic or cyber aggression most often include behaviors other than information seeking (Bennett, Guran,
Ramos, \& Margolin, 2011; Reed, Tolman, \& Ward, 2016; Stonard et al., 2014). For example, digital or cyber dating abuse includes spreading rumors about one's romantic partner or posting embarrassing photos in addition to surreptitiously looking at a partner's private information via a computer (Borrajo, Gámez-Guadix, \& Calvete, 2015; Reed, Tolman, \& Ward, 2016). Electronic or cyber aggression is a similar concept to digital or cyber dating abuse, although it can occur in friendships as well. Though many conceptualizations focus on behaviors such as bullying, harassment, or posting someone's private information, Bennett et al. (2011)'s definition also included obsessive monitoring.

Southworth et al. (2007) explained that cyberstalking consists of actions such as sending email threats or using the victim's online identity in addition to information seeking behaviors such as monitoring the victim's emails and using the Internet to compile the victim's personal information. Thus, not all behaviors included in the term cyberstalking are information seeking behaviors. Likewise, several scholars suggested electronic intrusion or electronic intrusiveness includes behaviors such as sending a copious amount of texts to a partner as a form of checking on them or pressure "for constant contact" (Reed, Tolman, Ward, \& Sayfer, 2016, p. $259)$ in addition to using social media to monitor a partner's activities (e.g., Doucette et al., 2018; Reed et al., 2016).

Moreover, the concepts of analytic labor (Karakayali \& Kilic, 2013) and interveillance (Christensen \& Jansson, 2015) both refer to observing others in one's social network. For example, people may monitor their peers on SNSs to learn about their attitudes, opinions, and behaviors such as voting (Bond, Settle, Farris, Jones, \& Fowler, 2017). These two terms also suggest that people categorize and evaluate their peers based on the information they find, which are actions that go beyond mere information seeking. For instance, Karakayali and Kilic (2013) defined analytic labor as the following:

...several distinct, albeit interrelated, sets of activities:

(i) regular observation of other users with the aim of finding out about their networks and relationships; (ii) classification and categorization of other users according to various criteria like their social background or patterns of online communication; (iii) evaluation and interpretation of online behavior of other users. (p. 175)

Similarly, interveillance involves both "social monitoring and expressivity, integrated through the technological archi- 
tecture of many contemporary media platforms" (Christensen \& Jansson, 2015, p. 1480). Notably, interveillance also refers to self-surveillance, which is outside of the scope of this review (Christensen \& Jansson, 2015).

Digilantism, cyber vigilantism, human flesh search, and websleuthing are typically conceptualized more broadly than just social information seeking as well. For example, Yardley, Lynes, Wilson, and Kelly (2018) suggested that digilantism involves "a range of activities, including searching for information, sharing and analysing photographs of suspects and drawing upon individual specialist knowledge" (p. 83). Yardley et al. (2018) similarly argued that websleuthing can include not only information seeking, but also "uploading documents, images and videos, commenting, debating, theorising, analysing, identifying suspects and attempting to engage with law enforcement and other organisations and individuals connected to the cases" (p. 82). Finally, human flesh search and cyber vigilantism often involve not only searching for information online, but also disclosing or publicizing it (Chia, 2019; Ong, 2012). However, Chia defined crowdsourced vigilantism in purely information seeking terms: "a collaborative information search conducted by Internet users in a form of crowdsourcing" (p. 2).

Social information seeking specific terms. Other concepts identified in this synthesis refer exclusively to online social information seeking, but they are broad terms that encompass a number of online information seeking behaviors. Ubiquitous surveillance concerns the capture of personal data via technology (Oulasvirta, Suomalainen, Hamari, Lampinen, \& Karvonen, 2014). Although this term is mostly used to refer to mass surveillance by organizations and government agencies, Oulasvirta et al. (2014) suggested it may also include many other instances of individual surveillance such as an acquaintance viewing someone's Facebook profile to steal their identity. Exotic surveillance occurs when people "actively monitor the victims' whereabouts by bugging computers or mobile technologies" (Tokunaga \& Aune, 2017, p. $1455)$, and mediated voyeurism is "the consumption of others' real and unguarded lives" (Wang, 2015, p. 468). Mediated voyeurism is sometimes used interchangeably with mediated surveillance (Ouwerkerk \& Johnson, 2016). Additionally, Tokunaga (2016) distinguished online surveillance from online (social) information seeking. According to Tokunaga, online social information seeking refers to searching for personal information, such as general interests, about others via the Internet (Stefanone et al., 2013; Tokunaga, 2016). However, online surveillance is "a special case of online information seeking" in that it is "more acutely targeted at specific relational information" (Tokunaga, 2016, p. 173).

Furthermore, Tokunaga (2011) defined interpersonal electronic surveillance (IES) as "surreptitious strategies individuals use over communication technologies to gain awareness of another user's offline and/or online behaviors" (p. 706). Tokunaga suggested that IES is neither positive nor negative in nature, and the term encompasses a number of surveillance and monitoring behaviors. For instance, IES would include lateral surveillance (Andrejevic, 2005) and participatory surveillance (Albrechtslund, 2008). Andrejevic (2005) described lateral surveillance as an individual's use of technology to keep track of peers, whereas participatory surveillance is "a type of surveillance where people willingly keep watch on each other through social media" (Fulton \& Kibby, 2017, p. 189). Both are conceptually similar to synoptic surveillance, wherein "users monitor one another's activities" (Fernback, 2013, p. 13). IES also includes online monitoring (Stewart, Dainton, \& Goodboy, 2014), partner monitoring (Muise et al., 2014) and cyber or technology privacy invasion (Wright, 2017). Tokunaga (2011) explicitly argued that IES does not describe surveillance performed by organizations (i.e., a collective), but it does cover surveillance done by business associates (i.e., individuals). Thus, IES would include cybervetting, which occurs when a human resources employee or other personnel management worker uses non-institutional online tools such as SNSs to learn personal information about a current or prospective employee (Berkelaar \& Buzzanell, 2014). Cybervetting is conceptually similar to social media assessments (Roth et al., 2016) and social recruiting (Root \& McKay, 2014), as both refer to using social media to screen job applicants.

Generally, concepts that refer to social information are conceptualized as involving social information seeking specifically. Such terms include social browsing (e.g., Wise et al., 2010), social information seeking (e.g., Rui, Covert, Stefanone, \& Mukherjee, 2015), social investigation (e.g., Wise et al., 2010), social network surfing (e.g., Giannakos, Chorianopoulos, Giotopoulos, \& Panayiotis Vlamos, 2013), social searching (e.g., Lampe, Ellison, \& Steinfield, 2006), social information consumption (Krasnova et al., 2015), and social surveillance (Park, Shin, \& Ju, 2019). Other terms, such as patient-targeted Googling (e.g., Chester et al., 2017), MAP-SNS (Vandenbosch, \& Eggermont, 2016), scandal mining (Trottier, 2018), creeping (e.g., Child \& Starcher, 2016), Facebook stalking (e.g., Muise 
et al., 2014), snooping (Derby et al., 2012), and the information seeking strategies outlined in uncertainty reduction theory (e.g., Ramirez et al., 2002, 2016) also specifically address social information seeking behaviors.

Summary of scope of the behaviors. Overall, it appears some terms describe social information seeking specifically. Notably, these terms are often incorporated in articles where the primary focus of the study is finding information or addressing uncertainty; theories focused on information seeking are also more likely to be cited. Broader terms are typically used when information seeking is among many possible behaviors that can be enacted, and the focus of the study is on the broader collective of these behaviors. Terms also differ in whether they are conceptually defined as purely online behaviors or are behaviors that can occur via a variety of channels.

\section{Seekers and Targets of Information Seeking}

Several concepts are used in reference to particular types of information seekers or targets. Within the reviewed articles, conceptualizations implied seekers such as romantic partners, friends, peers, parents, employers, healthcare professionals, and concerned or interested citizens. Definitions specified romantic partners, friends or peers, children, employees, patients, politicians, criminals, people who violated a social norm, and deceased individuals as targets. Other concepts were explicitly defined without a specific information seeking target in mind.

Romantic partners. Current, former, or potential romantic partners were the most frequently specified seekers and targets in our review (e.g., Derby et al., 2012; Marshall, 2012; Muise et al., 2014). The term partner monitoring, and a subset of behaviors termed Facebook partner monitoring, refer to repeated checking of a romantic partner's SNS profile (Darvell et al., 2011; Muise et al., 2014). Online monitoring was used in a similar sense (Stewart et al., 2014), and Seidman, Langlais, and Havens (2019) defined the more general term monitoring as "passive consumption of romantic partners' Facebook content" (p. 54). Snooping has also been defined as "investigating (without the partner's knowledge or permission) a romantic partner's private communication (e.g. text messages, cell phone and email)" (Derby et al., 2012, p. 333). However, snooping and the uncertainty reduction information seeking strategies can be used for other targets too (Hawk, Becht, \& Branje, 2015).
Moreover, electronic intrusion or electronic intrusiveness has been defined in reference to a current romantic partner: "a form of cyber dating abuse that includes monitoring a partners' location, whom a partner is talking to, and other private information via technology and social networking sites" (Doucette, 2018, p. 1). Likewise, Lopez (2017) used the term electronic surveillance to refer to "actively demanding access or covertly obtaining access to boyfriends' electronic devices and accounts as a means of investigating suspected infidelity" (p. 37). On the other hand, post-relationship contact and tracking is used in reference to a former romantic partner rather than a current partner (Lee \& O'Sullivan, 2014). Adolescent dating violence and abuse (Stonard et al., 2014) and the subset of behaviors termed technology-assisted adolescent dating violence and abuse (Stonard, 2019) are "directed towards a current or former romantic partner by the other within the context of an adolescent (10-18 years old) dating relationship" (Stonard et al., 2014, p. 393).

The targets of cyberstalking are not always romantic partners, but current or ex-romantic partners can be targets for cyberstalking. Hence, in their research, Smoker and March (2017) specifically referred to intimate partner cyberstalking as "cyberstalking behavior towards current, former, or potential intimate partners" (p. 391). Obsessive relational intrusion also involves "the unwanted pursuit of an intimate relationship" (Marshall et al., 2012, p. 521). Furthermore, Brem et al. (2019) distinguished cyberstalking from cyber monitoring:

Unlike cyber stalking, which more often occurs with former romantic partners and may be perpetrated to terrorize or regain a relationship with the victim (Spitzberg \& Cupach, 2001; Spitzberg \& Hoobler, 2002), some aspects of cyber monitoring may be mutually agreeable to current romantic partners, and may even be considered as ways of enhancing the relationship (Norton \& Baptist, 2014). (p. 411)

Friends or peers. Many conceptualizations refer to information seeking and monitoring amongst peers or friends. For example, Rui et al. (2015) stated that online information seeking consists of "monitoring Facebook friends" (p. 498), and Bryant and Marmo (2009) described surveillance as "monitoring friends' Facebook profiles" (p. 138). Andrejevic (2005) narrowed the term surveillance somewhat and suggested that lateral surveillance, which is similar to participatory surveillance (Albrechtslund, 2008), should be used for information seeking about family, prospective love interests, and friends. Specifically, they defined lateral surveillance as "not 
the top-down monitoring of employees by employers, citizens by the state, but rather the peer-to-peer surveillance of spouses, friends, and relatives" (Andrejevic, 2005, p. 481). However, Andrejevic seemingly placed more emphasis on surveilling friends, as "peer monitoring" or "peer surveillance" are used to describe lateral surveillance throughout the paper. Additionally, doing homework occurs when people "conduct social media investigations of potential friends" (Standlee, 2019, p. 770), and MAP-SNS involves monitoring attractive peers (Vandenbosch \& Eggermont, 2016). Lastly, according to Burke, Marlow, and Lento (2010), consumption involves an Internet user monitoring friends' posted content and public conversations with others.

Parents and children. Reading private emails may be seen as a form of mediated or computer-based privacy invasions, which are terms that describe parents' intrusion on children's privacy via electronic means (Kennedy-Lightsey \& Frisby, 2016; Ledbetter et al., 2010). Parental monitoring also refers to checking up on a child's activities via the Internet or Internetbased applications, either covertly or overtly (Livingstone \& Helsper, 2008).

Employees and potential employees. Berkelaar and colleagues often use the concept cybervetting in their work (Berkelaar, 2014; Berkelaar, Birdsell, \& Scacco, 2016; Berkelaar \& Buzzanell, 2014, 2015; Berkelaar, Scacco, \& Birdsell, 2015). Cybervetting is used exclusively in reference to a current or potential employee as a target of information seeking, and Berkelaar (2014) described the concept as a form of extractive information seeking (Ramirez et al., 2002). The definitions of cybervetting in extant literature are nearly identical to those provided for social recruiting (El Ouirdi et al., 2016) and social media assessments (Roth et al., 2016), as both refer to using websites or SNSs to collect information to use in employment decisions.

Health care providers and patients. One term, patienttargeted Googling, clearly targets individuals who are receiving medical treatment. This concept refers to "searching online for information about patients" (Clinton et al., 2010, p. 103). This search can occur via search engines such as Google or via social media (Chester, Walthert, Gallagher, Anderson, \& Stitely, 2017).

Citizens and politicians. Another term targets politicians or those running for office. Specifically, scandal mining occurs when people "actively search targeted political actors on open or otherwise accessible data sources, including but not limited to popular social media platforms" (Trottier,
2018, p. 894).

Online detectives, criminals, norm violators, or deceased individuals. As in the case of crowdsourced vigilantism (Chia, 2019), individual Internet users collaborate to conduct the information seeking behaviors outlined in cyber vigilantism (Chia, 2019), digilantism (Schwarz \& Richey, 2019), and the delectably named human flesh search (e.g., Chao \& Tao, 2012; Wang et al., 2010). For example, Chen and Sharma (2011) defined human flesh search as "a joint effort by thousands of online participants to retrieve information in a collaborative manner" (p. 50). Websleuthing may also be done by groups of Internet users; however, websleuths "also operate alone - often with a view to investigating a specific crime which has affected them as victims or secondary victims" (Yardley et al., 2018, p. 104).

Moreover, the terms cyber vigilantism, digilantism, and human flesh search are frequently used to refer to information seeking about a criminal or norm violator (e.g., someone who has committed a social offense by being extremely rude to others). For example, cyber vigilantism is defined as "a newly emerging practice whereby people expose misconducts and identify culprits through collaboratively searching and publicizing information using the Internet" (Chia, 2019, p. 1). Likewise, human flesh search has been defined as "the direct involvement of netizens collectively tracking down and publishing on the Internet information that might help to solve a crime or the personal information of someone who has engaged in corrupt practices or immoral behaviors" (Chang \& Poon, 2017, pp. 1913-1914) and "mediated search processes whereby online participants collectively find demographic and geographic information about deviant individuals" (Cheong \& Gong, 2010, p. 472). However, other scholars argue that although the term human flesh search most often applies to wrongdoers, it can refer to information seeking about nearly anyone, such as celebrities or potential love interests (Pan, 2010).

Websleuthing is also used to refer to information seeking about a criminal, although it can include searching for information about crime victims or anyone else involved in a criminal case as well (Yardley et al., 2019). Similarly, DeGroot (2014) used the term rubbernecking to refer to people viewing or becoming "involved in the events surrounding a death or traumatic accident of a person they do not personally" (p. 80). However, Baruh and Cemalcilar (2015) defined rubbernecking more broadly.

Unspecified. Admittedly, some concepts are not target- 
oriented. For example, Fox et al. (2013) argued that creeping is not defined by the target of information seeking. Facebook stalking, which has been conceptualized as a more aggressive form of creeping (Trottier, 2012), also does not specify a target. Several scholars suggested that when people are social browsing, they are not looking for a specific person. Rather, they are looking for personal information that interests them about any individual within their network (e.g., Asghar, 2015; Baruh \& Cemalc1lar, 2015; Wise et al., 2010). This definition is almost identical to that of profile browsing (Metzger, Wilson, \& Zhao, 2018), social information consumption (Krasnova et al., 2015), passive usage (Verduyn et al., 2015), and passive consumption of social news (Burke et al., 2011), and it only slightly differs from social network surfing, which involves browsing information about friends of friends (Giannakos et al., 2013; Joinson, 2008). However, others noted that social browsing refers to seeking information specifically about people whom the seeker does not know offline (Joinson, 2008; Ivana, 2013; Lampe et al., 2006; Marwick, 2012).

Other concepts suggest that information seekers have a target in mind, although the particular target is not specified within the conceptualization. For example, several scholars indicated that social searching is goal-oriented, and users look through the profile of a specific target person they know offline. The target person could be anyone the searcher chooses to focus on (Ivana, 2013; Joinson, 2008; Lampe et al., 2006; Quan-Haase \& Young, 2010; Wise et al., 2010). Social searching is conceptually similar to how some scholars have used the term social information seeking (Burke, Kraut, \& Marlow, 2011; Ellison, Steinfield, \& Lampe, 2011; Tian, 2016). Lastly, Tokunaga (2011) suggested interpersonal electronic surveillance is "a mindful and goal-oriented behavior in which contacts of all sorts, including close friends, romantic partners, business associates, or family members, can be placed under surveillance" (p. 706).

Summary of targets and seekers. In sum, some online social information seeking concepts, such as partner monitoring and cybervetting, have been used in reference to certain targets of information seeking. Others refer to specific seekers (e.g., parental monitoring). Some concepts also suggest that the specific target is identified by the information seeker engaging in the behavior or that there is no specific target at all. In many cases, the target or type of target is associated with certain motivations for information seeking.

\section{Motivations for Information Seeking}

As multiple scholars have argued, people search for information about others via the Internet with a motivation or purpose in mind (Joinson, 2008; $\mathrm{Ku}, \mathrm{Chu}, \&$ Tseng, 2013; Ouwerkerk \& Johnson, 2016; Ramirez et al., 2002). Two of the more problematic motivations described in existing conceptual definitions include threat or control and distrust or suspicion. Other motivations commonly identified include uncertainty reduction; relationship maintenance or acquiring social capital; reconnection; curiosity; care or concern; and establishing a sense of social justice, identifying missteps, or exacting punishment.

Uncertainty reduction. Following uncertainty reduction theory (Berger \& Calabrese, 1975), several researchers have described various passive, active, or interactive social information seeking strategies people use on SNSs to reduce uncertainty in developing romantic relationships (Fox \& Anderegg, 2014; Fox et al., 2013; Gibbs, Ellison, \& Lai, 2011), about new acquaintances (Antheunis, Valkenburg, \& Peter, 2010), and about people they knew long ago (Ramirez et al., 2016). Ramirez et al. (2002) also described extractive strategies, such as searching on Google, in relation to reducing uncertainty.

People may engage in creeping on a potential romantic partner to reduce uncertainty as well. In particular, Huber and DeGroot (2017) defined creeping as "the intentional pursuit of information to reduce uncertainty usually without aggressive or negative intentions" (p. 34). Likewise, Wise et al. (2010) defined social searching as the following: "social searching refers to the act of looking for specific information about offline acquaintances with the goal of knowing them better" (p. 556). Lastly, doing homework is described as investigating potential friends "to determine if a relationship continues" (Standlee, 2019, p. 770), which echoes Berger and Bradac's (1982) claims that people engage in uncertainty reduction strategies when interacting with another person has the potential to be rewarding or when people expect to interact again in the future.

Distrust or suspicion. Lopez (2017) defined electronic surveillance as "actively demanding access or covertly obtaining access to boyfriends' electronic devices and accounts as a means of investigating suspected infidelity" (p. 37), whereas Tokunaga (2016) argued that "online surveillance behaviors are borne out of personal or circumstantial suspicion or anxiety" (p. 173). Other scholars suggest that people engage in online social information seeking behaviors when they 
suspect their target has lied to them face-to-face. For instance, Facebook investigating is defined as "spying on certain people to check if they had been telling the truth" (Stiff, 2019, p. 64). Finally, Samp and Palevitz (2014) stated the following regarding Facebook stalking:

Facebook stalking can function in two ways. A partner concerned about a potential relational transgression either online or in a face-to-face context can use social networking sites to gather evidence to either alleviate or confirm suspicions that a partner is spending time or engaging in questionable conversations and actions with another. Alternatively, stalking may simply be a maintenance mechanism used to keep track of the events and experiences of a significant other and to see how the relationship is reported to others. (p. 479)

Thus, Facebook stalking may be motivated by suspicion or relationship maintenance.

Relational maintenance or acquiring social capital. Some terms refer to behaviors meant to sustain the existing state of the relationship (i.e., relational maintenance; Canary $\&$ Stafford, 1992). For example, participatory surveillance is a "way of maintaining friendships by checking up on information other people share" (Albrechtslund, 2008, p. 7). This motivation may reflect a concept known as fear of missing out (Przybylski, Murayama, DeHaan, \& Gladwell, 2013). Relatedly, social capital refers to "the benefits individuals derive from their social relationships and interactions: resources such as emotional support, exposure to diverse ideas, and access to non-redundant information" (Ellison et al., 2011, p. 873). Putnam (2000) identified two types of social capital. Bonding social capital refers to benefits derived from close relationships, whereas bridging social capital encompasses benefits from casual acquaintances or weak ties. Some researchers argued social information seeking, or more specifically online social information seeking, is motivated by cultivating and accessing bridging social capital (e.g., Ellison et al., 2011; Rui et al., 2015; Tian, 2016), which notably differs from our broader conceptualization of this term. For example, Ellison et al. (2011) stated social information seeking involves "using the site to 'check out' or 'learn more about' proximate latent or very weak ties" (p. 887), and Rui et al. (2015) stated it involves "searching information about acquaintances with whom users are newly connected via Facebook" (p. 499). On the other hand, social searching has been defined as "the desire to maintain and reconnect with offline connections" (Quan-Hasse \& Young, 2010, p. 353). Indeed, Park et al. (2015) stated that by using SNSs to increase their knowledge about offline connections, "social searchers can increase their awareness of the offline social network and thereby increase their social capital" (p. 602).

Reconnection. Similarly, some people are motivated to engage in online social information seeing behaviors to renew an old relationship. As noted above, social searching can be driven by reconnection (Quan-Hasse \& Young, 2010). Likewise, post-relationship contact and tracking reflects "efforts to maintain or re-establish contact with an ex-partner or to track their whereabouts, new partnerships or activities" (Lee \& O'Sullivan, 2014, p. 96), whereas obsessive relational intrusion has been defined as "the unwanted pursuit of an intimate relationship, particularly with an ex-romantic partner" (Marshall, 2012, p. 521).

Curiosity. Some conceptualizations claim that people engage in online social information seeking when they are curious as well. For example, Tokunaga (2016) argued that "online information seeking is motivated by general curiosity about another individual" (p. 173). Additionally, Baruh and Cemalcilar (2015) pointed out that rubbernecking is often characterized by a "morbid curiosity" (p. 507).

Care or concern. Fuchs (2011) argued that monitoring was distinct from surveillance because monitoring is driven by "care, benefits, solidarity, aid and co-operation" (p. 137). A few other scholars seem to echo this conceptualization of monitoring as born out of interest and care for a partner (e.g., Seidman, Langlais, \& Havens, 2019). But, not all definitions of monitoring share this emphasis on care (e.g., Sample \& Palevitz, 2014; Stewart, Dainton, \& Goodboy, 2014).

Resolve social injustice, identify missteps, or exact punishment. Digilantism is "intended to punish or bring others to account" (Schwarz \& Richey, 2019, p. 221). Along the same lines, human flesh search is often said to be "motivated by a desire for 'truth' and 'justice"" and the desire to "solve a social injustice or exact punishment on a perceived violator of the laws and norms of society" (Pantumsinchai, 2018, p. 764). Chang and Poon (2017) likewise stated that human flesh search involves seeking "information that might help to solve a crime or the personal information of someone who has engaged in corrupt practices or immoral behaviors, often with the aim of shaming and punishing them to reinstate legal or moral justice" (pp. 1913-1914). However, Chen and Sharma (2011) recognized that although human flesh search is most often motivated by a desire to punish someone, in a 
minority of cases, human flesh search can be driven by other motivations: "While it has been used for soliciting help and for uncovering the truth of miseries, human flesh search is best known for exposing individual privacy and launching name-and-shame campaigns to punish those who conduct unacceptable behavior" (p. 53). Finally, scandal mining "identifies a broader range of gaffes and missteps, especially when these are sufficient to discredit a political actor" (Trottier, 2018, p. 895).

Threat or control. Some conceptual definitions suggest people engage in online social information seeking in an effort to control and threaten their target. For example, cyber privacy invasion has been defined as "the use of digital communication to infringe upon the autonomy of another by gaining information about the victim without his or her consent" (Crane, Umehira, Berbary, \& Easton, 2018, p. 400). Consistent with U.S. law, a considerable number of scholars have suggested that harm or threat to a target is a common motive or perceived motive for cyberstalking (e.g., Marcum \& Higgins, 2019; Marcum, Higgins, \& Poff, 2016; Southworth et al., 2007; Spitzberg \& Hoobler, 2002; Strawhun, Adams, $\&$ Huss, 2013). For example, Marcum and Higgins (2019) defined cyberstalking as "the use of the Internet and other technological devices (e.g., computers, cellular telephones, pads) to monitor or harass another person in a threatening way" (p. 647), and Kircaburun et al. (2018) described cyberstalking as "malicious" (p. 265). For some, the motivation of threat is important for distinguishing cyberstalking from obsessive relational intrusion. As Spitzberg and Hoobler (2002) noted, people engaging in obsessive relational intrusion rarely intend to harm their targets, although the targets may perceive the behavior as threatening.

Additionally, Fuchs (2011) posited that surveillance is a harmful practice. Specifically, Fuchs used the motives of control and threat in his definition of surveillance: "surveillance is the collection of data on individuals or groups that are used so that control and discipline of behaviour can be exercised by the threat of being targeted by violence" (p. 136). However, Albrechtslund (2008) argued that surveillance does not necessarily entail control or differences in power, especially when considering forms of participatory surveillance. Lastly, electronic aggression (Bennett et al., 2011), technologyassisted adolescent dating violence and abuse (Stonard, 2019), the broader adolescent dating violence and abuse (Stonard et al., 2014, Stonard et al., 2017), and digital or cyber dating abuse (Reed, Tolman, \& Ward, 2016) can occur when the informa- tion seeker desires to control, threaten, or humiliate their romantic partners or friends. For example, Stonard et al. (2014) suggested adolescent dating violence and abuse refers to "behaviors that are threatening, controlling, violent, abusive, harassment or stalking" (p. 393), and Reed, Tolman, and Ward (2016) defined digital dating abuse as "a pattern of behaviors that control, pressure, or threaten a dating partner using a cell phone or the Internet" (p. 1556).

Summary of motivations. Many conceptualizations included the information seeker's motivations. In some cases, this is because information seeking is part of a broader collective of behaviors that is defined by the motivation. Scholars should be careful about including motivations in their conceptualizations unless this is an intentional constraint on the scope of a term's application. Several scholars have argued that seekers have multiple motivations for searching (e.g., Ouwerkerk \& Johnson, 2016; Tokunaga, 2016), and that these motivations fluctuate based on the seeker, the target, and various contextual factors.

\section{Intensity}

When looking at the relative intensity of online social information seeking behavior, we examined two factors: time and scope. Time included the frequency of behavior over time as well as the overall amount of time invested. Regarding scope, we considered the depth of information seeking (i.e., how extensively the seeker dug into a particular source) as well as the breadth (i.e., the range of sources or sites the seeker examined).

Time. Just as some concepts are not target-oriented, a few concepts are not defined in relation to time. For example, creeping is typically not identified by time spent searching the target's Facebook profile (Fox et al., 2013). In fact, the absence of a time marker is what most easily distinguishes creeping from Facebook stalking. Facebook stalking is characterized by frequently revisiting a target's profile page (Fox et al., 2013; Trottier, 2012). This frequency is what Facebook stalking has in common with cyberstalking. Consistent with legal definitions, several conceptualizations indicate that cyberstalking involves repeated actions over time (Cavezza \& McEwan, 2014; Finn, 2004; Southworth et al., 2007; Strawhun et al., 2013; Tokunaga \& Aune, 2017), and Spitzberg and Hoobler (2002) stated that cyberstalking is never an isolated event.

Researchers also conceptualize Facebook partner monitor- 
ing as a repeated activity (Darvell et al., 2011), and other scholars argued that surveillance is habitual or sustained (Lee, Ho, \& Lwin, 2017; Pearce \& Vitak, 2016). Researchers have suggested that interpersonal electronic surveillance is a form of "persistent monitoring" (Fox \& Tokunaga, 2015, p. 491), "frequent scouring" (Marcum et al., 2018, p. 718), or "excessively checking others' Facebook profiles" (Marshall, 2012, p. 521). However, Tokunaga (2011), who first defined the concept, argued that the term could be used to refer to a single incidence of information seeking. Digital dating abuse, electronic intrusion, and obsessive relational intrusion also consist of frequent or repeated information seeking behaviors (Chaulk \& Jones, 2011; Reed, Tolman, \& Ward, 2016; Spitzberg \& Hoobler, 2002). Mediated lurking involves a "prolonged use of Facebook to try to discover information about another" (Child \& Starcher, 2016, p. 484), and social surveillance has been conceptualized as "ongoing eavesdropping, investigation, gossip and inquiry that constitutes information gathering by people about their peers, made salient by the social digitization normalized by social media" (Marwick, 2012, p. 382). Trottier (2018) also described scandal mining as "a prolonged and scattered scrutiny of archived and often long-forgotten content" (p. 894).

On the other hand, rubbernecking often occurs in response to a tragic event such as death (DeGroot, 2014), so the frequency of the behavior likely fades as time passes and curiosity is satisfied. Cybervetting, social recruiting, and social media assessments may also be relatively short-term activities for any given information target, as employers mainly engage in these behaviors during the hiring process or when making personnel changes (Berkelaar \& Buzzanell, 2014; El Ouirdi et al., 2016; Roth et al., 2016). Additionally, Chen and Sharma (2011) noted that "human flesh search is able to collect the requested information in a short amount of time" (p. 55).

Scope. The depth and breadth of information seeking also distinguish online social information seeking concepts. The depth of information sought ranged from mere interest in a post that the seeker stumbled across to a "deep dive" into the entire profile or Internet history of a target. For example, social searching (Asghar, 2015) and creeping are generally conceptualized as more involved than more passive behaviors such as Instagram browsing (Yang, 2016), lurking (Osatuyi, 2015; Park, Lee, \& Kim, 2012), or passive consumption of social news (Burke et al., 2011). Creeping may entail "perusing content: a few pages of wall posts, or a photo album" (Trottier, 2012, pp. 324-325)" or "involves scrutinizing a person's Facebook profile, photos, posts, and friends" (Child \& Starcher, p. 484). At the same time, creeping involves less in-depth searching than Facebook stalking. At times, Facebook stalking may have an obsessive component to it (Meenagh, 2015), possibly parallel to cyberstalking. This may explain why Facebook stalking is also associated with information seeking for a long period of time, whereas creeping is not (Fox et al., 2013). Obsessive relational intrusion has an implied intensity as well due to the obsessive nature of the pursuit of intimacy (Chaulk \& Jones, 2011). Finally, Trottier (2018) stated scandal mining "involves a prolonged and scattered scrutiny of archived and often long-forgotten content" (p. 894). In other words, the information seeker must search in-depth about a politician to find a scandal.

Summary of intensity. We found some terms used time, depth, or breadth of searching within their conceptualizations. There are some cases in which intensity should be described in the conceptualization; for example, legal definitions of stalking clarify that there must be multiple incidents over time for it to be considered a criminal offense. Otherwise, imprecise indications of intensity in conceptualizations may lead to widely varying applications and operationalizations of terms.

\section{Collective Analysis and Limitations}

In sum, there are many online social information seeking terms used in extant literature. We identified 73 of them and explained how they are similar or different in their existing conceptualizations. Specifically, we found that terms differ in the scope of the included behaviors. Some terms address both online and offline behaviors, whereas others reflect actions that take place entirely online. A few terms are even specific to certain platforms such as Facebook or Instagram. Other terms differ in whether they address social information seeking specifically or encompass behaviors that go beyond information seeking.

Another distinction between terms is the seekers or targets of information seeking associated with the term. These can include romantic partners; friends or peers; parents and children; employees or potential employees; healthcare providers and patients; citizens and politicians; and online detectives and criminals, norm violators, or deceased individuals. Various motivations also underlie online social information seeking behaviors. In particular, some terms are used in relation to uncertainty reduction, distrust or suspi- 
cion, relational maintenance or acquirement of social capital, reconnection, curiosity, care or concern, threat or control, or the identification of missteps or enactment of punishment. Finally, different terms are used to describe variations in the intensity of information seeking, whether that intensity is due to the repeated, time-consuming nature of the information seeking or the depth to which people go to uncover information about another person from one or many sources.

Although we focused our review on the literature most relevant to communication, there are obvious limitations to this approach. We did not query every database across the social sciences, instead focusing on the areas most germane to interpersonal-level research and theorizing; inevitably there are terms we have missed. We gleaned work representative of several fields, but we acknowledge that our choice of approach may perpetuate the very problem we have noted in our review. We also chose to constrain our analysis to discernible definitions and conceptualizations we could extract to preserve precise semantics rather than attempting to reverse-engineer a conceptualization based on authors' argumentation or operationalization. We did not think inferring a conceptualization was appropriate, as it increases the chances of misrepresenting the authors' intentions.

Upon review, we note with some surprise that some literatures are not represented in our final term list. For example, we expected to see areas such as online celebrity fandom, development of parasocial relationships online, and more online social information seeking about political candidates (e.g., Ancu \& Cozma, 2009; Weeks \& Southwell, 2010) represented. Often, authors used, but never conceptualized, an online social information seeking term. Thus, clearly defining and conceptualizing terms is one possible suggestion for future research.

\section{Suggestions for Future Research}

After analyzing the multitude of online social information seeking concepts in the extant literature, we identified several ways the field could improve. Here, we present suggestions for researchers interested in examining online social information seeking behaviors in the future. We also provide a decision tree for researchers to use to help select appropriate terms moving forward.

\section{Know the Literature}

First and foremost, scholars studying online phenomena need to acknowledge the novelty fallacy, an erroneous belief that a behavior is new or fundamentally different because it occurs in a technological context (Fox \& McEwan, 2020). Human behavior preceded the Internet and still occurs beyond its boundaries, yet recent scholarship on various forms of social information seeking behaviors that occur online all too often ignores this fact. Researchers should also be mindful of the novelty fallacy in their own research: it is unlikely a study is the first to examine a particular phenomenon. Rather, it is often the case that the same phenomenon has been studied in a different sub-field or context, or there is another term to describe it.

Scholars should perform due diligence and conduct thorough literature searches on information seeking behavior across channels. Narrowing searches to recent literature or studies on a particular platform is an unwise practice that overlooks decades of relevant research. As scholars and scientists contributing to the public understanding, it is our responsibility to be experts and understand the full breadth and depth of the topics we research before we embark on a new line of study. Otherwise, we clutter the literature and databases with redundant terms and do not meaningfully advance knowledge on social information seeking.

\section{Determine the Main Purpose of the Study}

After garnering the scope of historical knowledge, researchers should consider what they really want to know. Specifically, researchers should determine if they are mainly interested in social information seeking behaviors, if they are interested in a particular technology, or if they are interested in how social information seeking manifests online. Unfortunately, many studies in this review claimed to contribute to knowledge of online social information seeking behaviors, but they often did not examine both the behavior and the technological aspects together, and instead focused on one or the other. Below we further elaborate these issues and provide guidance on how to overcome each of these problems in future research.

Behavior-focused. In this review, studies that were more focused on social information seeking behavior typically treated the technological aspect crudely (e.g., "online" or "... on [platform]" was added to information seeking questions). 
When they employed theories, usually they were theories focused on interpersonal or structural aspects that did not consider communication channels. Rarely were efforts made to test, challenge, or expand theories considering channel characteristics. Generally, these behavior-focused studies were able to replicate relationships observed in other contexts (e.g., personality traits predicting information seeking) or describe or report the incidence of behaviors limited to the context of study (e.g., how people engaged in information seeking specifically via one iteration of Facebook). As a result, they adopted terms reflecting a very narrow scope (e.g., Facebook partner-monitoring, digital dating abuse). Given the theoretical framing or stated applications of these studies, it is unclear why the scope is narrowed. For example, few conclusions can be drawn about the motivations, scope, and effects of relational abuse if researchers are only examining what happens online in isolation of what is happening across channels; in fact, they may be getting a false impression due to the limitations of their approach.

Technology-focused. Based on their argumentation, hypotheses, or literature reviews, some papers in this review seemed to be more focused on the technological context. These papers were more likely to overlook existing information seeking literature, particularly older studies and research outside of online contexts. Another consistent issue was platform-specificity. If the goal is to understand online social information seeking, constraining research to a single platform is undesirable for a number of reasons. First, platforms shut down frequently and often unexpectedly, which may interrupt research or limit the shelf life of any study that is too centered around a particular platform or its features. Second, users, audiences, and practices differ across platforms, which can present confounds and limit the generalizability of findings on one platform to any other context. Third, changes in technological capabilities, ownership, audiences, practices, laws, and particularly finances have driven platforms to make dramatic changes that may render research efforts null if they are too platform-specific. For example, information seeking on Facebook used to be quite different: before the advent of the newsfeed in 2006, users would have to visit another person's page to view their updates. Now that the newsfeed is the entry point for Facebook users, the visibility of others' posts is much greater, and users are much more likely to have incidental exposure to social information even if they are not seeking information about a specific target.
Best practices. In the future, researchers should be mindful of perpetuating the false online versus offline dichotomy. If they are intending to broadly understand a form of social information seeking behavior, they must look beyond often artificial boundaries and examine what is happening across and within channels. If researchers want to garner a deeper understanding of social information seeking and how it manifests online specifically, they must develop expertise in both interpersonal and technology literatures. They must also consider on a deep level how different elements of known social information seeking processes may be influenced by or interact with elements of technologies. However, unless researchers have a clearly delineated reason for choosing a particular platform, not merely its current popularity or convenience, they should not artificially constrain the scope of their research as it limits generalizability and contributions to theorizing.

For example, a study finding that people monitor their romantic partners on Instagram teaches us nothing specific about Instagram; it simply indicates that Instagram is a context in which this behavior does or does not occur. If the couple uses other social networking sites such as Facebook or Twitter, the behavior may occur there as well. It may also be happening through any number of other channels (e.g., face-to-face observation; monitoring texts, phone calls, or email). Thus, a study such as this teaches us little about the scope, degree, or intensity of romantic partner monitoring in relationships. Moreover, we cannot tell if monitoring on Instagram is more frequent or more intense than other channels. We have no idea if there is something specific and special about Instagram that enables or predicts this behavior, which may provide some insights on its likelihood to occur in other channels. As a result, a study such as this offers minimal contributions to our understanding of the technology. It also only provides a limited look at romantic partner monitoring behavior that occurs in the narrow context of a single online site, so it offers minimal contributions to our understanding of the behavior or the relationship between the behavior and technologies. Some ways researchers may address these issues are to include multiple platforms or channels within a study; replicate across different platforms and channels; attempt to account for known differences if possible (e.g., sample from different age groups if the platform's audience is skewed); or use platform-neutral stimuli in experiments. A focus on affordances is another way to ensure more durability in research. 
Examining affordances is crucial for understanding how and why social information seeking may or may not differ across channels. Fox and McEwan (2020) elaborated three roles for technologies: are technologies merely accommodating social information seeking, enabling a behavior previously observed in other channels? Have these technologies amplified the process, increasing the frequency, efficiency, or range of the behavior? Or, have technologies fundamentally altered social information seeking, meaning we require new or radically modified theories to explain it? Understanding the role of affordances will help scholars make this determination. For instance, social information seeking could be dramatically altered if the accessibility or visibility of certain information is increased. As an example, physiological trackers could be linked to a target's SNS profile, and anyone viewing it could know their current heart rate or how many steps they have taken today. Algorithms designed to recognize patterns in behavior or link existing "de-identified" datasets present a growing threat to anonymous behavior online. Tracking and surveillance technologies continue to grow, ranging from "nanny cams" and "doorbell" monitors to always-listening voice assistants and from mobile apps to GPS-trackers and drones. Although it is impossible for scholarly conceptualizations to stay completely ahead of these moving targets (Fox \& McEwan, 2020), researchers should consider how widely their findings may translate and how long they may persist in an ever-changing technological landscape.

\section{Employ Conceptual Clarity and Consistency}

Our review indicates that a rather alarming number of terms have been used to refer to online social information seeking. We found that definitions were nearly identical for different terms, suggesting these terms are describing the same information seeking behavior. To illustrate, cybervetting (Berkelaar, 2014, 2017a, 2017b), social media assessment (Roth et al., 2016), and social recruiting (E1 Ouirdi et al., 2016) all describe using the Internet, and especially social media, for information seeking about a current or potential employee. In each case, a current employee uses the Internet to check up on the activities of another person to help make job-related decisions. Likewise, social browsing (Wise et al., 2010) and social information consumption (Krasnova et al., 2015) are both terms often used to describe seeking non-specific information about no one in particular online. The information seeker is just generally interested in learning something about anyone. As another example, human flesh search (Chao \& Tao, 2012; Chen \& Sharma, 2011; Cheong \& Gong, 2010), digilantism (Yardley et al., 2018), cyber vigilantism (Chia, 2019), and crowdsourced vigilantism (Chia, 2019) are all terms describing an informal collection of various individuals scouring the Internet in search of information about a particular target who is most often a perceived wrongdoer.

One explanation for the abundance of terms is that interest in communication channels and social behavior has grown considerably beyond the discipline of communication, and in its wake, jargon has proliferated. Regardless of whether jargon is driven by lack of careful literature searches (researchers are unaware of existing literature and conceptualizations), ego (researchers attempting to make a name for themselves with a "new" term), or a lack of awareness of the scholastic repercussions, it is a scourge on scholarly progress for a number of reasons. From a practical perspective, it is necessary for scholars to share a common vocabulary so that they can conduct thorough literature searches and grasp the true scope of existing research, particularly across disciplines. Conceptual clarity is also necessary for sound, universal theorizing. Thus, the most obvious implication of our review is that scholars must stop generating and using unnecessary, repetitive, and excessively narrow terms.

The novelty fallacy seems to drive researchers to dump new jargon into the literature. In some cases, researchers were examining a very specific manifestation of information seeking behavior, but this does not necessarily warrant a new term. For example, patient-targeted Googling is only distinguished from other concepts by its target; the originators of this term clarified that it includes behaviors beyond using Google's search engine (Clinton et al., 2010), indicating the term was not only unnecessary, but also a misnomer. Another way the novelty fallacy emerged is that some studies focused solely on a newer platform (which, as previously noted, is generally inadvisable) were compelled to squeeze out new jargon. Although we did not uncover terms such as MySpace monitoring, WELL watching, or Vine-veillance in our review, these examples should underscore the short-sightedness in platform-specific terms. Conceptualizations of human behavior should not emerge with corporate branding nor an expiration date for their scholarly relevance.

There are a few valid reasons for new terminology to appear in the literature, and we did observe a handful of 
cases in our review. For example, in qualitative work, the audience may be unable to make sense of participants' comments and in vivo codes if researchers do not define the terms study participants use. Because creeping and Facebook stalking were used by study participants in both Trottier (2012) and Fox et al. (2013), these terms were defined. A1though these terms merited clarification for this purpose and have value in other contexts (e.g., linguistic research), this does not warrant scholars adopting, citing, and perpetuating such slang in place of established scholarly constructs. Unfortunately, we observed subsequent studies citing and incorporating these terms uncritically.

In summary, we strongly advise against introducing new and unnecessary jargon that is inconsistent with the existing literature and so narrowly defined as to prohibit its use in theorizing or application outside of a very constrained context. If a truly novel concept were to emerge, it may merit coining a new term; in our review, however, these were almost nonexistent. Going forward, researchers should help promote conceptual clarity by employing appropriate, existing terms and providing clear definitions within the scope of published articles.

Decision tree. To assist this effort, we have synthesized the existing literature and provided a truncated list of base terms in a decision tree to guide the adoption of terms and their conceptualizations (see Figure 1). Because the vast majority of social information seeking behaviors described in literature occur across channels, and currently little suggests that online social information seeking behavior requires theorizing independent of other channels, the base terms are independent of the online context. By using this decision tree, researchers can help consolidate existing terms, prevent the proliferation of redundant terms describing the same behaviors, and avoid creating unnecessary jargon.

Although our analysis identified trends in how scholars have conceptually defined social information seeking concepts thus far, we argued that some of those trends (e.g., limiting terms to a specific platform) are hindering progress in our field. As a result, our decision tree does not encourage scholars to continue with certain distinctions identified in the analysis of the current state of the literature (e.g., using platform-specific terms, including motivations within conceptual definitions). Rather, the base terms presented in the decision tree represent consistent and notable variations in social information seeking behavior identified in our analy- sis and rooted in decades of existing literature.

The first question in the decision tree addresses scope. To determine which term to use, scholars should first identify the behaviors of interest to them: are they focusing primarily on information seeking behavior or a broader behavior in which information seeking is only a part? For example, vigilantism is primarily conceptualized as involving both information seeking and other behaviors oriented toward enforcement and seeking justice by unofficial persons. Because this synthesis is exclusively about information seeking and does not provide insights about other behaviors beyond information seeking, scholars looking at these broader concepts (e.g., aggression, stalking) will need to consult additional extant literature when selecting one of the base terms to ensure fit.

If scholars are interested in information seeking concepts specifically, the next question in the decision tree addresses intensity in terms of time. In particular, the decision tree helps researchers distinguish between terms that represent ongoing, repeated behaviors and more short-term behaviors. This distinction is based on conceptual and legal precedent. However, given there is no clear operationalization or cut-off for depth or breadth of information seeking behaviors, we did not include these aspects of intensity in the decision tree. Rather than including depth and breadth of seeking behaviors in a conceptualization, we recommend that researchers operationalize depth and breadth as needed in their studies.

Similarly, motivation was intentionally excluded from the decision tree because seekers may have a variety of motivations or goals driving information seeking behavior and one conceptualization is unlikely to capture them all. Further, given the rich and vast information that may be uncovered online, motivations and goals may shift throughout the process. For instance, Lisa may be driven by curiosity to find out what happened to Bobby, her best friend from summer camp. She searches for him online and finds that, like her, he became a reporter, but landed a job at a more prestigious newspaper than Lisa. Now she begins to search for his bylines to engage in social comparison. One story has a picture of him, and suddenly she realizes that the awkward teen she knew is now a very attractive man. As Lisa is single, she abandons the newspaper site to start looking for more personal information about Bobby: is he single? While searching for photos of him with a partner, she finds his mug shot and learns he is currently in prison for arson. She starts collecting links about his arrest and trial to text to her other friends 


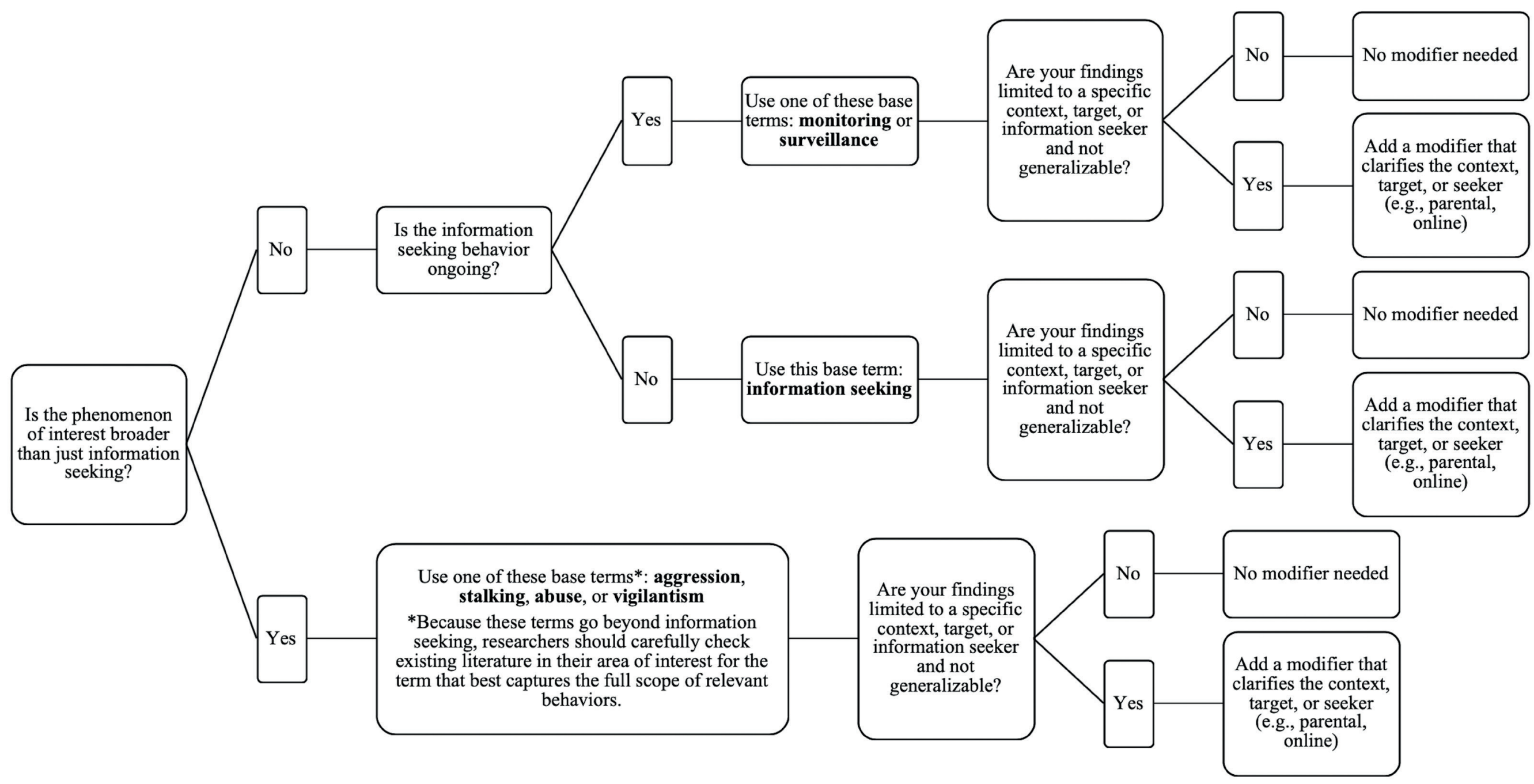

Figure 1. Decision tree for social information seeking terms 
from the camp. At various points, Lisa's behavior was motivated by curiosity, envy, and romantic interest, pursuing goals of satisfying curiosity, social comparison, reconnection, vetting romantic potential, and entertaining friends.

Finally, the decision tree helps scholars determine if modifiers are needed. Modifiers should only be used when findings are limited to a unique context, a specific target, or a particular information seeker and are not generalizable. For example, adding the word "parental" to the term monitoring may be a sensible clarification because the parentchild relationship is distinct from others due to familial ties, age differences, imbalanced power, and legal implications. Existing theorizing may also provide appropriate modifiers. For example, uncertainty reduction theory clarifies three different types of information seeking strategies contingent on the nature of interpersonal interaction involved in the process (passive, active, and interactive information seeking). For reasons noted previously, however, we discourage the use of platform-specific modifiers. When modifiers are used, we strongly advise scholars to add a standalone word rather than adding a prefix, hyphenating, or otherwise blending the two words. Creating such chimeras complicates the search process as they are not necessarily identified when searching the base concept. As an example, online surveillance is a better choice than cybersurveillance, cyber-surveillance, or cyberveillance.

Regardless of whether a modifier is used or not, researchers should always clearly conceptually define the base term within their paper. By focusing on conceptualizing base terms, researchers can better understand information seeking behaviors taking place in various contexts and help limit the number of online social information seeking terms in the literature. Additionally, regardless of which base term is used or whether a modifier is added, researchers should always include the term information seeking somewhere in their paper so that their paper can be found in searches on this topic. We specifically recommend social information seeking for clarity over other information seeking contexts (e.g., health information seeking). Researchers should also include their chosen terms in the title, abstract, and keywords whenever possible to enhance searchability.

\section{Conclusion}

In sum, this review examined 73 online social information seeking concepts from 186 articles. The terms were discussed in light of scope of the included behaviors, seekers and targets of information seeking, motivations for information seeking, and intensity of the information seeking. Based on this analysis, we provided some recommendations for future research and offered a decision tree to help researchers select terms. With increased attention to the particular concepts used in research, the discipline can move toward a more thorough understanding of online social information seeking behaviors.

\section{References}

*Adam, A. (2002). Cyberstalking and internet pornography: Gender and the gaze. Ethics and Information Technology, 4, 133143. doi: 10.1023/A:1019967504762

Afifi, W. A., \& Morse, C. R. (2009). Expanding the role of emotion in the theory of motivated information management. In T. D. Afifi \& W. A. Afifi (Eds.), Uncertainty, information management, and disclosure decisions: Theories and applications (pp. 87-105). New York, NY: Routledge.

Afifi, W. A., \& Weiner, J. L. (2004). Toward a theory of motivated information management. Communication Theory, 14, 167-190. doi: 10.1111/j.1468-2885.2004.tb00310.x

*Albrechtslund, A. (2008). Online social networking as participatory surveillance. First Monday, 13(3). doi: 10.5210/fm.v13i3.2142 Alexy, E. M., Burgess, A. W., Baker, T., \& Smoyak, S. A. (2005). Perceptions of cyberstalking among college students. Brief Treatment and Crisis Intervention, 5, 279-289. doi: 10.1093/brief-treatment/mhi020

Altman, I., \& Taylor, D. A. (1973). Social penetration: The development of interpersonal relationships. New York, NY: Holt, Rinehart \& Winston. 
Ancu, M., \& Cozma, R. (2009). MySpace politics: Uses and gratifications of befriending candidates. Journal of Broadcasting \& Electronic Media, 53, 567-583. doi: 10.1080/08838150903333064

*Andrejevic, M. (2005). The work of watching one another: Lateral surveillance, risk, and governance. Surveillance \& Society, 2, 479-497. doi: 10.24908/ss.v2i4.3359

*Antheunis, M. L., Valkenburg, P. M., Peter, J. (2010). Getting acquainted through social network sites: Testing a model of online uncertainty reduction and social attraction. Computers in Human Behavior, 26, 100-109. doi: 10.1016/j.chb.2009.07.005

*Asghar, H. M. (2015). Measuring information seeking through Facebook: Scale development and initial evidence of information seeking in Facebook Scale (ISES). Computers in Human Behavior, 52, 259-270. doi: 10.1016/j.chb.2015.06.005

*Ashby, G. A., O’Brien, A., Bowman, D., Hooper, C., Stevens, S., \& Lousada, E. (2015). Should psychiatrists 'Google' their patients?. BJPsych Bulletin, 39, 278-283. doi: 10.1192/pb.bp.114.047555

*Ashuri, T., \& Bar-Ilan, Y. (2017). Collective action recruitment in a digital age: Applying signaling theory to filtering behaviors. Communication Theory, 27, 70-91. doi: 10.1111/comt.12108

Atkin, C. K. (1972). Anticipated communication and mass media information-seeking. Public Opinion Quarterly, 36, 188-199. doi: $10.1086 / 267991$

*Baruh, L., \& Cemalcilar, Z. (2015). Rubbernecking effect of intimate information on Twitter: When getting attention works against interpersonal attraction. Cyberpsychology, Behavior, and Social Networking, 18, 506-513. doi: 10.1089/cyber.2015.0099

Baxter, L. A. (1988). A dialectical perspective on communication strategies in relationship development. In S. W. Duck (Ed.), A handbook of personal relationships: Theory, research, and interventions (pp. 257- 273). New York, NY: Wiley \& Sons.

Baxter, L. A., \& Wilmot, W. W. (1984). Secret tests: Social strategies for acquiring information about the state of the relationship. Human Communication Research, 11, 171-201. doi: 10.1111/j.1468-2958.1984.tb00044.xs

Becker, L. B., \& Doolittle, J. C. (1975). How repetition affects evaluations of and information seeking about candidates. Journalism Quarterly, 52, 611-617. doi: 10.1177/107769907505200401

*Belu, C. F., Lee, B. H., \& O'Sullivan, L. F. (2016). It hurts to let you go: Characteristics of romantic relationships, breakups, and the aftermath among emerging adults. Journal of Relationships Research, 7, 1-11. doi: 10.1017/jrr.2016.11

*Bennett, D. C., Guran, E. L., Ramos, M. C., \& Margolin, G. (2011). College students' electronic victimization in friendships and dating relationships: Anticipated distress and associations with risky behaviors. Violence and Victims, 26, 410-429. doi: 10.1891/0886-6708.26.4.410

*Benrazavi, R., Teimouri, M., \& Griffiths, M. D. (2015). Utility of parental mediation model on youth's problematic online gaming. International Journal of Mental Health Addiction, 13, 712-727. doi: 10.1007/s11469-015-9561-2

Berger, C. R. (1979). Beyond initial interaction: Uncertainty, understanding, and the development of interpersonal relationships. In H. Giles \& R. N. St. Clair (Eds.), Language and social psychology (pp. 122-144). Oxford: Basil Blackwell.

Berger, C. R., \& Bradac, J. J. (1982). Language and social knowledge: Uncertainty in interpersonal relations. London: Edward Arnold.

Berger, C., \& Calabrese, R. (1975). Some explorations in initial interaction and beyond: Toward a developmental theory of interpersonal communication. Human Communication Research, 1(2), 99-112. doi: 10.1111/j.1468-2958.1975.tb00258.x

*Berkelaar, B. L. (2014). Cybervetting, online information, and personnel selection: New transparency expectations and the emergence of a digital social contract. Management Communication Quarterly, 28, 479-506. doi: 10.1177/0893318914541966

*Berkelaar, B. L. (2017a). Different ways new information technologies influence conventional organizational practices and employment relationships: The case of cybervetting for personnel selection. Human Relations, 70, 1115-1140. doi: $10.1177 / 0018726716686400$

*Berkelaar, B. L. (2017b). How implicit theories help differentiate approaches to online impression management: A preliminary typology. New Media \& Society, 19, 2039-2058. doi: 10.1177/1461444816654136

*Berkelaar, B. L., Birdsell, J. L., \& Scacco, J. M. (2016). Storying the digital professional: How online screening shifts the primary site and authorship of workers' career stories. Journal of Applied Communication Research, 44, 275-295. doi: 10.1080/00909882.2016.11922 87 
*Berkelaar, B. L., \& Buzzanell, P. M. (2014). Cybervetting, person-environment fit, and personnel selection: Employers' surveillance and sensemaking of job applicants' online information. Journal of Applied Communication Research, 42, 456476. doi: 10.1080/00909882.2014.954595

*Berkelaar, B. L., \& Buzzanell, P. M. (2015). Online employment screening and digital career capital: Exploring employers' use of online information for personnel selection. Management Communication Quarterly, 29, 84-113. doi: $10.1177 / 0893318914554657$

*Berkelaar, B. L., Scacco, J. M., \& Birdsell, J. L. (2015). The worker as politician: How online information and electoral heuristics shape personnel selection and careers. New Media \& Society, 17, 1377-1396. doi: 10.1177/1461444814525739

*Bond, R. M., Settle, J. E., Fariss, C. J., Jones, J. J., \& Fowler, J. H. (2017). Social endorsement cues and political participation. Political Communication, 34, 261-281. doi: 10.1080/10584609.2016.1226223

Bond, B. J., Hefner, V., \& Drogos, K. L. (2009). Information-seeking practices during the sexual development of lesbian, gay, and bisexual individuals: The influence and effects of coming out in a mediated environment. Sexuality \& Culture, 13, 32-50. doi: 10.1007/s12119-008-9041-y

*Borrajo, E., Gámez-Guadix, M., \& Calvete, E. (2015). Cyber dating abuse: Prevalence, context, and relationship with offline dating aggression. Psychological Reports: Relationships \& Communications, 116, 565-585. doi: 10.2466/21.16.PR0.116k22w4

*Botan, C. (1996). Communication work and electronic surveillance: A model for predicting panoptic effects. Communication Monographs, 63, 293-313. doi: 10.1080/03637759609376396

boyd, d. (2011). Social network sites as networked publics: Affordances, dynamics, and implications. In Z. Papacharissi (Ed.), A networked self: Identity, community, and culture on social network sites (pp. 39-58). New York, NY: Routledge.

*Brandtzæg, P. B., Lüders, M., Skjetne, J. H. (2010). Too many Facebook "friends"? Content sharing and sociability versus the need for privacy in social network sites. International Journal of Human-Computer Interaction, 26, 1006-1030. doi: 10.1080/10447318.2010.516719

Brashers, D. E. (2001). Communication and uncertainty management. Journal of Communication, 51, 477-497. doi: 10.1111/j.1460-2466.2001.tb02892.x

Brashers, D. E., Neidig, J. L., Haas, S. M., Dobbs, L. K., Cardillo, L. W., \& Russell, J. A. (2000). Communication in the management of uncertainty: The case of persons living with HIV or AIDS. Communication Monographs, 67, 63-84. doi: 10.1080/03637750009376495

*Brem, M. J., Spiller, L. C., \& Vandehey, M. A. (2015). Online mate-retention tactics on Facebook are associated with relationship aggression. Journal of Interpersonal Violence, 30, 2831-2850. doi: 10.1177/0886260514554286

*Brem, M. J., Florimbio, A. R., Grigorian, H., Wolford-Clevenger, C., Elmquist, J., Shorey, R. C., ...Stuart, G. L. (2019). Cyber abuse among men arrested for domestic violence: Cyber monitoring moderates the relationship between alcohol problems and intimate partner violence. Psychology of Violence, 9, 410-428. doi: 10.1037/vio0000130

*Bryant, E. M., \& Marmo, J. (2009). Relational maintenance strategies on Facebook. The Kentucky Journal of Communication, 28, 129-150. Retrieved from http://digitalcommons. trinity.edu/ cgi/viewcontent.cgi?article=1005\&context=hct_facult

*Bumgarner, B. A. (2007). You have been poked: Exploring the uses and gratifications of Facebook among emerging adults. First Monday, 12(11). Retrieved from https://firstmonday.org/article/view/2026/1897

*Burke, M., Kraut, R., \& Marlow, C. (2011). Social capital on Facebook: Differentiating uses and users. In CHI '11 Proceedings of the SIGCHI conference on human factors in computing systems (pp. 571-580). New York, NY: ACM. doi: 10.1145/1978942.1979023

*Burke, M., Marlow, C., \& Lento, T. (2010). Social network activity and social well-being. In Proceedings of the SIGCHI conference on human factors in computing systems (pp. 1909-1912). New York, NY: ACM. doi: 10.1145/1753326.1753613

Canary, D. J., \& Stafford, L. (1992). Relational maintenance strategies and equity in marriage. Communication Monographs, 59, 243-267. doi: 10.1080/03637759209376268

Carr, C. T., \& Walther, J. B. (2014). Increasing attributional certainty via social media: Learning about others one bit at a time. Journal of Computer-Mediated Communication, 19, 922-937. doi: 10.1111/jcc4.12072

*Cavezza, C., \& McEwan, T. E. (2014). Cyberstalking versus off-line stalking in a forensic sample. Psychology, Crime \& Law, 20, 955-970. doi: 10.1080/1068316X.2014.893334 
${ }^{*}$ Chang, L. Y. C., \& Poon, R. (2017). Internet vigilantism: Attitudes and experiences of university students toward cyber crowdsourcing in Hong Kong. International Journal of Offender Therapy and Comparative Criminology, 61, 1912-1932. doi: $10.1177 / 0306624 \mathrm{X} 16639037$

${ }^{*}$ Chao, C., \& Tao, Y. (2012). Human flesh search: A supplemental review. Cyberpsychology, Behavior, and Social Networking, 15, 350-356. doi: 10.1089/cyber.2011.0481

*Chaulk, K., \& Jones. T. (2011). Online obsessive relational intrusion: Further concerns about Facebook. Journal of Family Violence, 26, 245-254. doi: 10.1007/s10896-011-9360-x

${ }^{*}$ Chen, R., \& Sharma, S. K. (2011). Human flesh search - Facts and issues. Journal of Information Privacy and Security, 7, 50-71. doi: 10.1080/15536548.2011.10855905

*Cheong, P. H., \& Gong, J. (2010). Cyber vigilantism, transmedia collective intelligence, and civic participation. Chinese Journal of Communication, 3, 471-487. doi: 10.1080/ 17544750.2010.516580

${ }^{*}$ Chester, A. N., Walthert, S. E., Gallagher, S. J., Anderson, L. C., \& Stitely, M. L. (2017). Patient-targeted Googling and social media: A cross-sectional study of senior medical students. BMC Medical Ethics, 18, 1-8. doi: 10.1186/s12910-017-0230-9

${ }^{*}$ Chia, S. C. (2019). Seeking justice on the web: How news media and social norms drive the practice of cyber vigilantism. Social Science Computer Review. Advance online publication. doi: 10.1177/0894439319842190

${ }^{*}$ Child, J. T., \& Starcher, S. C. (2016). Fuzzy Facebook privacy boundaries: Exploring mediated lurking, vague-booking, and Facebook privacy management. Computers in Human Behavior, 54, 483-490. doi: 10.1016/j.chb.2015.08.035

${ }^{*}$ Christensen, M., \& Jansson, A. (2015). Complicit surveillance, interveillance, and the question of cosmopolitanism: Toward a phenomenological understanding of mediatization. New Media \& Society, 17, 1473-1491. doi: 10.1177/1461444814528678

Clarke, P. (1973). Teenagers' coorientation and information-seeking about pop music. American Behavioral Scientist, 16, 551566. doi: 10.1177/000276427301600406

*Clinton, B. K., Silverman, B. C., \& Brendel, D. H. (2010). Patient-targeted Googling: The ethics of searching online for patient information. Harvard Review of Psychiatry, 18, 103-112. doi: 10.3109/10673221003683861

*Courtois, C., All, A., \& Vanwynsberghe, H. (2012). Social network profiles as information sources for adolescents' offline relations. Cyberpsychology, Behavior, and Social Networking, 15, 290-295. doi: 10.1089/cyber.2011.0557

${ }^{*}$ Crane, C. A., Umehira, N., Berbary, C., \& Easton, C. J. (2018). Problematic alcohol use as a risk factor for cyber aggression within romantic relationships. The American Journal on Addictions, 27, 400-406. doi: 10.1111/ajad.12736

Crowley, J. L., \& High, A. C. (2018). Parents' information seeking during adolescent career development: a test of the theory of motivated information management. Journal of Applied Communication Research, 46, 348-367. doi: 10.1080/00909882.2018.1468570

*Darvell, M. J., Walsh, S. P., \& White, K. M. (2011). Facebook tells me so: Applying the theory of planned behavior to understand partner-monitoring behavior on Facebook. Cyberpsychology, Behavior, and Social Networking, 14, 717-722. doi: 10.1089/cyber.2011.0035

*de Arujo, R. C., \& Kowacs, C. (2019). Patient-targeted "Googling:" When therapists search for information about their patients online. Psychodynamic Psychiatry, 47, 27-38. doi: 10.1521/pdps.2019.47.1.27

*DeGroot, J. M. (2014). "For whom the bell tolls": Emotional rubbernecking in Facebook memorial groups. Death Studies, 38, 79-84. doi: 10.1080/07481187.2012.725450

*Derby, K., Knox, D., \& Easterling, B. (2012). Snooping in romantic relationships. College Student Journal, 46, 333-343. Retrieved from http://www.projectinnovation.biz/csj.html

*Dhillon, G., \& Smith, K. J. (2019). Defining objectives for preventing cyberstalking. Journal of Business Ethics, 157, 137-158. doi: 10.1007/s10551-017-3697-x

*Doucette, H., Collibee, C., Hood, E., Stone, D. I. G., DeJesus, B., \& Rizzo, C. J. (2018). Perpetration of electronic intrusiveness among adolescent females: Associations with in-person dating violence. Journal of Interpersonal Violence. Advance online publication. doi: 10.1177/0886260518815725 
*Dreßing, H., Bailer, J., Anders, A., Wagner, H., \& Gallas, C. (2014). Cyberstalking in a large sample of social network users: Prevalence, characteristics, and impact upon victims. Cyberpsychology, Behavior, and Social Networking, 17, 61-67. doi: 10.1089/cyber/2012.0231

*Drouin, M., Miller, D. A., \& Dibble, J. L. (2014). Ignore your partners' current Facebook friends; beware the ones they add! Computers in Human Behavior, 35, 483-488. doi: 10.1016/j.chb.2014.02.032

*Duerksen, K. N., \& Woodin, E. M. (2019). Technological intimate partner violence: Exploring technology-related perpetration factors and overlap with in-person intimate partner violence. Computers in Human Behavior, 98, 223-231. doi: 10.1016/j.chb.2019.05.001

*Eichenberg, C., \& Herzberg, P. Y. (2016). Do therapists Google their patients? A survey among psychotherapists. Journal of Medical Internet Research, 18(1), 1-9. doi: 10.2196/ jmir.4306

*E1 Ouirdi, M., El Ouirdi, A., Segers, J., \& Pais, I. (2016). Technology adoption in employee recruitment: The case of social media in Central and Eastern Europe. Computers in Human Behavior, 57, 240-249. doi: 10.1016/j.chb.2015.12.043

*Ellison, N. B., Steinfield, C., \& Lampe, C. (2011). Connection strategies: Social capital implications of Facebook-enabled communication practices. New Media \& Society, 13, 873-892. doi: 10.1177/1461444810385389

*Fernback, J. (2013). Sousveillance: Communities of resistance to the surveillance environment. Telematics and Informatics, 30, 11-21. doi: 10.1016/j.tele.2012.03.003

*Finn, J. (2004). A survey of online harassment at a university campus. Journal of Interpersonal Violence, 19, 468-483. doi: $10.1177 / 0886260503262083$

*Fox, J., \& Anderegg, C. (2014). Romantic relationship stages and social networking sites: Uncertainty reduction strategies and perceived relational norms on Facebook. Cyberpsychology, Behavior, and Social Networking, 17, 685-691. doi: 10.1089/cyber.2014.0232

Fox, J., \& McEwan, B. (2017). Distinguishing technologies for social interaction: The perceived social affordances of communication channels scale. Communication Monographs, 84, 298-318. doi: 10.1080/03637751.2017.1332418

Fox, J., \& McEwan, B. (2020). Social media. In M. B. Oliver, A. Raney, \& J. Bryant (Eds.), Media effects: Advances in theory and research (4th ed., pp. 373-388). New York, NY: Routledge.

*Fox, J., \& Tokunaga, R. S. (2015). Romantic partner monitoring after breakups: Attachment, dependence, distress, and post-dissolution online surveillance via social networking sites. Cyberpsychology, Behavior, and Social Networking, 18, 491498. doi: 10.1089/cyber.2015.0123

*Fox, J., Warber, K. M., \& Makstaller, D. C. (2013). The role of Facebook in romantic relationship development: An exploration of Knapp's relational stage model. Journal of Social and Personal Relationships, 30, 771-794. doi: 10.1177/0265407512468370

*Frison, E., \& Eggermont, S. (2016). Exploring the relationships between different types of Facebook use, perceived online social support, and adolescents' depressed mood. Social Science Computer Review, 34, 153-171. doi:10.1177/0894439314567449

*Fuchs, C. (2011). New media, web 2.0 and surveillance. Sociology Compass, 5, 134-147. doi: 10.1111/j.1751-9020.2010.00354.x

*Fuchs, C., \& Trottier, D. (2015). Towards a theoretical model of social media surveillance in contemporary society. Communications, 40, 113-135. doi: 10.1515/commun-2014-0029

*Fulton, J. M., \& Kibby, M. D. (2017). Millennials and the normalization of surveillance on Facebook. Continuum, 31, 189199. doi: 10.1080/10304312.2016.1265094

*Gao, L. (2016). The emergence of the human flesh search engine and political protest in China: Exploring the Internet and online collective action. Media, Culture, \& Society, 38, 349-364. doi: 10.1177/0163443715610493

${ }^{*}$ Gao, L., \& Stanyer, J. (2014). Hunting corrupt officials online: The human flesh search engine and the search for justice in China. Information, Communication, \& Society, 17, 814-829. doi: 10.1080/1369118X.2013.836553

${ }^{*}$ Giannakos, M. N., Chorianopoulos, K., Giotopoulos, K., \& Vlamos, P. (2013). Using Facebook out of habit. Behavior \& Information Technology, 32, 594-602. doi: 10.1080/0144929X.2012.659218

${ }^{*}$ Gibbs, J. L., Ellison, N. B., \& Lai, C. (2011). First comes love, then comes Google: An investigation of uncertainty reduction strategies and self-disclosure in online dating. Communication Research, 38, 70-100. doi: 10.1177/0093650210377091 
Griffin, R. J., Neuwirth, K., Dunwoody, S., \& Giese, J. (2004). Information sufficiency and risk communication. Media Psychology, 6, 23-61. doi: 10.1207/s1532785xmep0601_2

Guerrero, L. K., \& Afifi, W. A. (1998). Communicative responses to jealousy as a function of self-esteem and relationship maintenance goals: A test of Bryson's dual motivation model. Communication Reports, 11, 111-122. doi: 10/1080/08934219809367693

*Hawk, S. T., Becht, A., \& Branje, S. (2015). "Snooping" as a distinct parental monitoring strategy: Comparisons with overt solicitation and control. Journal of Research on Adolescence, 26, 443-458. doi: 10.1111/jora.12204

*Hedenus, A., Backman, C., \& Håkansson, P. (2019). Whom do you know? Recruiters' motives for assessing jobseekers' online networks. The International Journal of Human Resource Management. Advance online publication. doi: $10.1080 / 09585192.2019 .1579245$

*Hellevik, P. M. (2019). Teenagers' personal accounts of experiences with digital intimate partner violence and abuse. Computers in Human Behavior, 92, 178-187. doi: 10.1016/j.chb.2018.11.019

Helsper, E. J., \& Whitty, M. T. (2010). Netiquette within married couples: Agreement about acceptable online behavior and surveillance between partners. Computers in Human Behavior, 26, 916-926. doi: 10.1016/j.chb.2010.02.006

Hogan, T. P., \& Brashers, D. E. (2009). The theory of communication and uncertainty management: Implications from the wider realm of information behavior. In T. D. Afifi \& W. A. Afifi (Eds.), Uncertainty, information management, and disclosure decisions: Theories and applications (pp. 45-66). New York, NY: Routledge.

*Horsman, G., \& Conniss, L. R. (2015). An investigation of anonymous and spoof SMS resources used for the purposes of cyberstalking. Digital Investigation, 13, 80-93. doi: 10.1016/j.diin.2015.04.001

*Howard, D. E., Debnam, K. J., \& Strausser, A. (2019). "I'm a stalker and proud of it": Adolescent girls' perceptions of the mixed utilities associated with Internet and social networking use in their dating relationships. Youth \& Society, 51, 773792. doi: $10.1177 / 0044118 X 17716948$

*Huber, C., \& DeGroot, J. M. (2017). A grounded theory model of perceptions toward creeping and stalking behaviors. Journal of the Communication, Speech, \& Theatre Association of North Dakota, 30, 32-41. Retrieved from https://sites.google. $\mathrm{com} / \mathrm{site} / \mathrm{cstandv} 2 /$ publications/journal

*Humphreys, L. (2011). Who's watching whom? A study of interactive technology and surveillance. Journal of Communication, 61, 575-595. doi: 10.1111/j.1460-2466.2011.01570.x

*Ivana, G. (2013). A postmodern panopticon: Lateral surveillance on Facebook. Global Media Journal: Mediterranean Edition, $8,1-14$.

*Jansson, A. (2012). Perceptions of surveillance: Reflexivity and trust in a mediated world (the case of Sweden). European Journal of Communication, 27, 410-427. doi: 10.1177/0267323112463306

*Joinson, A. N. (2008). Looking at, looking up or keeping up with people?: Motives and use of Facebook. In CHI Proceedings of the SIGCHI conference on human factors in computing systems (pp. 1027-1036). New York, NY: ACM. doi: 10.1145/1357054.13572 13

*Karakayali, N., \& Kilic, A. (2013). More network conscious than ever? Challenges, strategies, and analytic labor of users in the Facebook environment. Journal of Computer-Mediated Communication, 18, 175-193. doi: 10.1111/jcc4.12005

Katz, E., Blumler, J. G., \& Gurevitch, M. (1973). Uses and gratifications research. Public Opinion Quarterly, 37, 509-523. doi: $10.1086 / 2747854$

*Kennedy-Lightsey, C. D., \& Frisby. B. N. (2016). Parental privacy invasion, family communication patterns, and perceived ownership of private information. Communication Reports, 29, 75-86. doi: 10.1080/08934215.2015.1048477

*Kircaburun, K., Jonason, P. K., \& Griffiths, M. D. (2018). The dark tetrad traits and problematic social media use: The mediating role of cyberbullying and cyberstalking. Personality and Individual Differences, 135, 264-269. doi: 10.1016/j.paid.2018.07.034

Knapp, M. L. (1978). Social intercourse: From greeting to goodbye. Needham Heights, MA: Allyn \& Bacon.

Knobloch, S., Carpentier, F. D., \& Zillmann, D. (2003). Effects of salience dimensions of informational utility on selective exposure to online news. Journalism \& Mass Communication Quarterly, 80, 91-108. doi: 10.1177/107769900308000107 
Knobloch, L. K., \& Solomon, D. H. (2002). Information seeking beyond initial interaction: Negotiating relational uncertainty within close relationships. Human Communication Research, 28, 243-257. doi: 10.1111/j.1468-2958.2002.tb00806.x

*Krasnova, H., Widjaja, T., Buxmann, P., Wenninger, H., Benbasat I. (2015) Research note-why following friends can hurt you: An exploratory investigation of the effects of envy on social networking sites among college-age users. Information Systems Research, 26, 585-605. doi: 10.1287/isre.2015.0588

$\mathrm{Ku}, \mathrm{Y} ., \mathrm{Chu}, \mathrm{T} ., \quad \&$ Tseng, C. (2013). Gratifications for using CMC technologies: A comparison among SNS, IM, and e-mail. Computers in Human Behavior, 29, 226-234. doi: 10.1016/j.chb.2012.08.009

*Lai, C. (2019). Motivations, usage, and perceived social networks within and beyond social media. Journal of Computer-Mediated Communication, 24, 126-145. doi: 10.1093/jcmc/zmz004

*Lampe, C., Ellison, N., \& Steinfield, C. (2006, November 8-10). A face(book) in the crowd: Social searching vs. social browsing. In Proceedings of the ACM special interest group on computer-supported cooperative work (pp. 167-170). New York, NY: ACM. doi: 10.1145/1180875.1180901

*Law, D. M., Shapka, J. D., \& Olson, B. F. (2010). To control or not to control? Parenting behaviours and adolescent online aggression. Computers in Human Behavior, 26, 1651-1656. doi: 10.1016/j.chb.2010.06.013

*Ledbetter, A. M., Heiss, S., Sibal, K., Lev, E., Battle-Fisher, M., \& Shubert, N. (2010). Parental invasive and children's defensive behaviors at home and away at college: Mediated communication and privacy boundary management. Communication Studies, 61, 184-204. doi: 10.1080/10510971003603960

*Lee, B. H., \& O'Sullivan, L. F. (2014). The ex-factor: Characteristics of online and offline postrelationship contact and tracking among Canadian emerging adults. Canadian Journal of Human Sexuality, 23, 96-105. doi: 10.3138/cjhs.2415

*Lee, E. W. J., Ho, S. S., \& Lwin, M. O. (2017). Explicating problematic social network sites use: A review of concepts, theoretical frameworks, and future directions for communication theorizing. New Media \& Society, 19, 308-326. doi: $10.1177 / 1461444816671891$

*LeFebvre, L., Blackburn, K., \& Brody, N. (2015). Navigating romantic relationships on Facebook: Extending the relationship dissolution model to social networking environments. Journal of Social and Personal Relationships, 32, 78-98. doi: $10.1177 / 0265407514524848$

*Lewis, J., \& West, A. (2009). 'Friending': London-based undergraduates' experience of Facebook. New Media \& Society, 11, 1209-1229. doi: 10.1177/1461444809342058

*Livingstone, S., \& Helsper, E. J. (2008). Parental mediation of children's internet use. Journal of Broadcasting \& Electronic Media, 54, 581-599. doi: 10.1080/08838150802437396

*Lopez, V. (2017). Love is a battlefield: Mexican American girls' strategies for avoiding players. Youth \& Society, 49, 23-45. doi: 10.1177/0044118X14521223

*Lu, Y., Van Ouytsel, J., Walrave, M., Ponnet, K., \& Temple, J. R. (2018). Cross-sectional and temporal associations between cyber dating abuse victimization and mental health and substance use outcomes. Journal of Adolescence, 65, 1-5. doi: 10.1016/j.adolescence. 2018.02.009

*Lukacs, V., \& Quan-Haase, A. (2015). Romantic breakups on Facebook: New scales for studying post-breakup behaviors, digital distress, and surveillance. Information, Communication \& Society, 18, 492-508. doi: 10.1080/1369118X.2015.1008540

*Lyndon, A., Bonds-Raacke, J., \& Cratty, A. D. (2011). College students' Facebook stalking of ex-partners. Cyberpsychology, Behavior, and Social Networking, 14, 711-716. doi: 10.1089/cyber.2010.0588

Maguire, K. C. (2007). "Will it ever end?" A (re)examination of uncertainty in college student long-distance dating relationships. Communication Quarterly, 55, 415-432. doi: 10.1080/01463370701658002

*Marcum, C. D., \& Higgins, G. E. (2019). Examining the effectiveness of academic scholarship on the fight against cyberbullying and cyberstalking. American Journal of Criminal Justice, 44, 645-655. doi: 10.1007/s12103-019-09482-8

*Marcum, C. D., Higgins, G. E., \& Nicholson, J. (2017). I'm watching you: Cyberstalking behaviors of university students in romantic relationships. American Journal of Criminal Justice, 42, 373-388. doi: 10.1007/s12103-016-9358-2 
*Marcum, C. D., Higgins, G. E., \& Nicholson, J. (2018). Crossing boundaries online in romantic relationships: An exploratory study of the perceptions of impact on partners by cyberstalking offenders. Deviant Behavior, 39, 716-731. doi: 10.1080/01639625. 2017.1304801

*Marcum, C. D., Higgins, G. E., \& Poff, B. A. (2016). Exploratory investigation on theoretical predictors of the electronic leash. Computers in Human Behavior, 61, 213-218. doi:10.1016/j.chb.2016.03.010.

*Marshall, T. C. (2012). Facebook surveillance of former romantic partners: Associations with postbreakup recovery and personal growth. Cyberpsychology, Behavior, and Social Networking, 15, 521-526. doi: 10.1089/cyber.2012.0125

*Marshall, T. C., Bejanyan, K., Di Castro, G., \& Lee, R. A. (2013). Attachment styles as predictors of Facebook-related jealousy and surveillance in romantic relationships. Personal Relationships, 20, 1-22. doi: 10.1111/j.1475-6811.2011.01393.x

*Marwick, A. (2012). The public domain: Social surveillance in everyday life. Surveillance \& Society, 9, 378-393. doi: $10.24908 /$ ss.v9i4.4342

*Marx, G. T. (2004). What's new about the "new surveillance"? Classifying for change and continuity. Knowledge, Technology \& Policy, 17, 18-37. doi: 10.1007/BF02687074

*McEwan, B. (2013). Sharing, caring, and surveilling: An actor-partner interdependence model examination of Facebook relational maintenance strategies. Cyberpsychology, Behavior, and Social Networking, 16, 863-869. doi: 10.1089/cyber.2012.0717

*Meenagh, J. (2015). Flirting, dating, and breaking up within new media environments. Sex Education, 15, 458-471. doi: $10.1080 / 14681811.2015 .1033516$

*Melton, J., Miller, R., \& Salmona, M. (2018). University student use of Twitter and Facebook: A study of posting in three countries. Journal of Technical Writing and Communication, 48, 331-358. doi: 10.1177/0047281617724402

*Metzger, M. J., Wilson, C., \& Zhao, B. Y. (2018). Benefits of browsing? The prevelance, nature, and effects of profile consumption behavior in social network sites. Journal of Computer-Mediated Communication, 23, 72-89. doi: 10.1093/jcmc/zmx004

Miller, A. H., \& MacKuen, M. (1979). Learning about the candidates: The 1976 presidential debates. Public Opinion Quarterly, 43, 326-346. doi: 10.1086/268525

*Moor, L., \& Anderson, J. R. (2019). A systematic literature review of the relationship between dark personality traits and antisocial online behaviours. Personality and Individual Differences, 144, 40-55. doi: 10.1016/j.paid.2019.02.027

*Moriarty, L. J., \& Freiberger, K. (2008). Cyberstalking: Utilizing newspaper accounts to establish victimization patterns. Victims and Offenders, 3, 131-141. doi: 10.1080/155648 80801938169

*Muise, A., Christofedes, E., \& Desmarais, S. (2014). "Creeping” or just information seeking? Gender differences in partner monitoring in response to jealousy on Facebook. Personal Relationships, 21, 35-50. doi: 10.1111/pere.12014

*Myles, D., Benoit-Barné, C., \& Millerand, F. (2020). 'Not your personal army!' Investigating the organizing property of retributive vigilantism in a Reddit collective of websleuths. Information, Communication, \& Society, 23, 317-336, doi: 10.1080/1369118X.2018.1502336

${ }^{*}$ Omaggio, N. F., Baker, M. J., \& Conway, L. J. (2018). Have you ever Googled a patient or been friended by a patient? Social media intersects the practice of genetic counseling. Journal of Genetic Counseling, 27, 481-492. doi: 10.1007/s10897-017-0206-4

*Ong, R. (2012). Online vigilante justice Chinese style and privacy in China. Information \& Communications Technology Law, 21, 127-145. doi: 10.1080/13600834.2012.678653

*Osatuyi, B. (2015). Is lurking an anxiety-masking strategy on social media sites? The effects of lurking and computer anxiety on explaining information privacy concern on social media platforms. Computers in Human Behavior, 49, 324-332. doi: 10.1016/j.chb.2015.02.062

O'Sullivan, P. B., \& Carr, C. T. (2018). Masspersonal communication: A model bridging the mass-interpersonal divide. New Media \& Society, 20, 1161-1180. doi: 10.1177/1461444816686104

*Oulasvirta, A., Suomalainen, T., Hamari, J., Lampinen, A., \& Karvonen, K. (2014). Transparency of intentions decreases privacy concerns in ubiquitous surveillance. Cyberpsychology, Behavior, and Social Networking, 17, 633-638. doi: 10.1089/cyber.2013.0585 
*Ouwerkerk, J. W., \& Johnson, B. K. (2016). Motives for online friending and following: The dark side of social network site connections. Social Media + Society, 2, 1-13. doi: 10.1177/2056305116664219

*Pan. X. (2010). Hunt by the crowd: An exploratory qualitative analysis on cyber surveillance in China. Global Media Journal, 9(16). Retrieved from http://www.globalmediajournal. com/open-access/hunt-by-the-crowd-an-exploratory-qualitativeanalysis-on-cyber-surveillance-in-china.pdf

*Pantumsinchai, P. (2018). Armchair detectives and the social construction of falsehoods: An actor-network approach. Information, Communication, \& Society, 21, 761-778. doi: 10.1080/1369118X.2018.1428654

*Park, N., Lee, S., \& Kim, J. H. (2012). Individuals' personal network characteristics and patterns of Facebook use: A social network approach. Computers in Human Behavior, 28, 1700-1707. doi: 10.1016/j.chb.2012.04.009

*Park, M., Shin, J., \& Ju, Y. (2015). A taxonomy of social networking site users: Social surveillance and self-surveillance perspective. Psychology \& Marketing, 32, 601-610. doi: 10.1002/mar.20803

*Park, M., Shin, J., \& Ju, Y. (2019). Attachment styles and electronic word of mouth (e-WOM) adoption on social networking sites. Journal of Business Research, 99, 398-404. doi: 10.1016/j.jbusres.2017.09.020

*Pearce, K. E., \& Vitak, J. (2016). Performing honor online: The affordances of social media for surveillance and impression management in an honor culture. New Media \& Society, 18, 2595-2612. doi: 10.1177/1461444815600279

*Pempek, T. A., Yermolayeva, Y. A., \& Calvert, S. L. (2009). College students' networking experiences on Facebook. Journal of Applied Developmental Psychology, 30, 227-238. doi: 10.1016/j.appdev.2008.12.010

Przybylski, A. K., Murayama, K., DeHaan, C. R., \& Gladwell, V. (2013). Motivational, emotional, and behavioral correlates of fear of missing out. Computers in Human Behavior, 29, 1841-1848. doi: 10.1016/j.chb.2013.02.014

Putnam, R. D. (2000). Bowling alone: The collapse and revival of American community. New York, NY: Simon and Schuster.

${ }^{*}$ Qiu, L., Lin, H., Chiu, C., \& Liu, P. (2015). Online collective behaviors in China: Dimensions and motivations. Analyses of Social Issues and Public Policy, 15, 44-68. doi: 10.1111/asap.12049

${ }^{*}$ Quan-Haase, A., \& Young, A. L. (2010). Uses and gratifications of social media: A comparison of Facebook and instant messaging. Bulletin of Science, Technology, \& Society, 30, 350-361. doi: 10.1177/0270467610380009

${ }^{*}$ Quinn, K., \& Papacharissi, Z. (2018). The contextual accomplishment of privacy. International Journal of Communication, 12, 45-67. Available at https://ijoc.org/index.php/ijoc/ article/view/7016

Rains, S. A. (2018). Coping with illness digitally. Cambridge, MA: MIT Press.

*Ramirez, A., Sumner, E. M., \& Hayes, J. (2016). Reconnect on Facebook: The role of information seeking behavior and individual-and relationship-level factors. Cyberpsychology, Behavior, and Social Networking, 19, 494-501. doi: 10.1089/cyber.2015.0630

Ramirez, A., \& Walther, J. B. (2009). Information seeking and interpersonal outcomes using the internet. In T. D. Afifi \& W. A. Afifi (Eds.), Uncertainty, information management, and disclosure decisions: Theories and applications (pp. 67- 84). New York, NY: Routledge.

${ }^{*}$ Ramirez, A., Walther, J. B., Burgoon, J. K., \& Sunnafrank, M. (2002). Information-seeking strategies, uncertainty, and computer-mediated communication: Toward a conceptual model. Human Communication Research, 28, 213-228. doi: 10.1111/j.1468-2958.2002.tb00804.x

*Reed, L. A., Tolman, R. M., \& Safyer, P. (2015). Too close for comfort: Attachment insecurity and electronic intrusion in college students' dating relationships. Computers in Human Behavior, 50, 431-438. doi: 10.1016/j.chb.2015.03.050

*Reed, L. A., Tolman, R. M., \& Ward, L. M. (2016). Snooping and sexting: Digital media as a context for dating aggression and abuse among college students. Violence Against Women, 22, 1556-1576. doi: 10.1177/1077801216630143

${ }^{*}$ Reed, L. A., Tolman, R. M., \& Ward, L. M. (2017). Gender matters: Experiences and consequences of digital dating abuse victimization in adolescent dating relationships. Journal of Adolescence, 59, 79-89. doi: 10.1016/j.adolescence.2017.05.015

*Reed, L. A., Tolman, R. M., Ward, L. M., \& Safyer, P. (2016). Keeping tabs: Attachment anxiety and electronic intrusion in high school dating relationships. Computers in Human Behavior, 58, 259-268. doi: 10.1016/j.chb. 2015.12.019

*Reyns, B. W., Henson, B., \& Fisher, B. S. (2011). Being pursued online: Applying cyberlifestyle-routine activities theory to cyberstalking victimization. Criminal Justice and Behavior, 38, 1149-1169. doi: 10.1177/0093854811421448 
Rider, K. (2018). The privacy paradox: How market privacy facilitates government surveillance. Information, Communication \& Society, 21, 1369-1385. doi: 10.1080/1369118X.2017.1314531

${ }^{*}$ Root, T., \& McKay, S. (2014). Student awareness of the use of social media screening by prospective employers. Journal of Education for Business, 89, 202-206. doi: 10.1080/08832323.2013.848832

*Rote, W. M., \& Smetana, J. G. (2018). Within-family dyadic patterns of parental monitoring and adolescent information management. Developmental Psychology, 54, 2302-2315. doi: 10.1037/dev0000615

*Roth, P. L., Bobko, P., Van Iddekinge,C. H., \& Tatcher, J. B. (2016). Social media in employee-selection-related decisions: A research agenda for uncharted territory. Journal of Management, 42, 269-298. doi: 10.1177/0149206313503018

${ }^{*}$ Roth, P. L., Thatcher, J. B., Bobko, P., Matthews, K. D., Ellingson, J. E., \& Goldberg, C. B. (2020). Political affiliation and employment screening decisions: The role of similarity and identification processes. Journal of Applied Psychology, 105, 472-486. doi: 10.1037/ap10000422

Rubin, A. M. (2009). Uses-and-gratifications perspective on media effects. In J. Bryant \& M. B. Oliver, Media effects: Advances in theory and research (pp. 181-200). New York, NY: Routledge.

Rueda, H. A., Lindsay, M., \& Williams, L. R. (2015). "She posted it on Facebook": Mexican American adolescents' experiences with technology and romantic relationship conflict. Journal of Adolescent Research, 30, 419-445. doi: $10.1177 / 0743558414565236$

*Rui, J. R., Covert, J. M., Stefanone, M. A., \& Mukherjee, T. (2015). A communication multiplexity approach to social capital: On- and offline communication and self-esteem. Social Science Computer Review, 33, 498-518. doi: $10.1177 / 0894439314552803$

Saldaña, J. (2013). The coding manual for qualitative researchers (2nd ed.). Thousand Oaks, CA: SAGE.

*Samp, J. A., \& Palevitz, C. E. (2014). Managing relational transgressions as revealed on Facebook: The influence of dependence power on verbal versus nonverbal responses. Journal of Nonverbal Behavior, 38, 477-493. doi: 10.1007/s10919-014-0197-x

*Scherr, S., Toma, C. L., \& Schuster, B. (2019). Depression as a predictor of Facebook surveillance and envy: Longitudinal evidence from a cross-lagged panel study in Germany. Journal of Media Psychology: Theories, Methods, and Applications, 31, 196-202. doi: 10.1027/1864-1105/a000247

*Schwarz, K. C. (2019). Humanitarian humor, digilantism, and the dilemmas of representing volunteer tourism on social media. New Media \& Society, 21, 1928-1946. doi: 10.1177/1461444819834509

*Seidman, G., Langlais, M., \& Havens, A. (2019). Romantic relationship-oriented Facebook activities and the satisfaction of belonging needs. Psychology of Popular Media Culture, 8, 52-62. doi: 10.1037/ppm0000165

*Shaw, A. M., Timpano, K. R., Tran, T. B., \& Joormann, J. (2015). Correlates of Facebook usage patterns: The relationship between passive Facebook use, social anxiety symptoms, and brooding. Computers in Human Behavior, 48, 575-580. doi: 10.1016/j.chb.2015.02. 003

*Sheldon, P., \& Bryant, K. (2016). Instagram: Motives for its use and relationship to narcissism and contextual age. Computers in Human Behavior, 58, 89-97. doi: 10.1016/j.chb.2015.12.059

*Sheridan, L. P., \& Grant, T. (2007). Is cyberstalking different? Psychology, Crime and Law, 13, 627-640. doi: 10.1080/10683160701340528.

*Smith-Darden, J. P., Kernsmith, P. D., Victor, B. G., \& Lathrop, R. A. (2016). Electronic displays of aggression in teen dating relationships: Does the social ecology matter? Computers in Human Behavior, 67, 33-40. doi: 10.1016/j.chb.2016.10.015

*Smoker, M., \& March, E. (2017). Predicting perpetration of intimate partner cyberstalking: Gender and the dark tetrad. Computers in Human Behavior, 72, 390-396. doi: 10.1016/j.chb.2017.03.012

*Southworth, C., Finn, J., Dawson, S., Fraser, C., \& Tucker, S. (2007). Intimate partner violence, technology, and stalking. Violence Against Women, 13, 842-856. doi: 10.1177/1077801207302045

*Spitzberg, B. H., \& Hoobler, G. (2002). Cyberstalking and the technologies of interpersonal terrorism. New Media \& Society, 4, 71-92. doi: 10.1177/1461444802004001005 
*Standlee, A. (2019). Friendship and online filtering: The use of social media to construct offline social networks. New Media \& Society, 21, 770-785. doi: 10.1177/1461444818806844

*Stefanone, M. A., Hurley, C. M., \& Yang, Z. J. (2013). Antecedents of online information seeking. Information, Communication \& Society, 16, 61-81. doi: 10.1080/1369118X.2012.656137

*Stewart, M. C., Dainton, M., \& Goodboy, A. K. (2014). Maintaining relationships on Facebook: Associations with uncertainty, jealousy, and satisfaction. Communication Reports, 27, 13-26. doi: 10.1080/08934215.2013.845675

*Stiff, C. (2019). The dark triad and Facebook surveillance: How Machiavellianism, psychopathy, but not narcissism predict using Facebook to spy on others. Computers in Human Behavior, 94, 62-69. doi: 10.1016/j.chb.2018.12.044

*Stonard, K. E. (2019). Technology-assisted adolescent dating violence and abuse: A factor analysis of the nature of electronic communication technology used across twelve types of abusive and controlling behaviour. Journal of Child and Family Studies, 28, 105-115. doi: 10.1007/s10826-018-1255-5

*Stonard, K. E., Bowen, E., Lawrence, T. R., \& Price, S. A. (2014). The relevance of technology to the nature, prevalence, and impact of adolescent dating violence and abuse: A research synthesis. Aggression and Violent Behavior, 19, 390-417. doi: 10.1016/j.avb.2014.06.005

*Stonard, K. E., Bowen, E., Walker, K., \& Price, S. A. (2017). "They'll always find a way to get to you": Technology use in adolescent romantic relationships and its role in dating violence and abuse. Journal of Interpersonal Violence, 32, 2083-2117. doi: $10.1177 / 0886260515590787$

Stoycheff, E., Wibowo, K. A., Liu, J., \& Xu, K. (2017). Online surveillance's effect on support for other extraordinary measures to prevent terrorism. Mass Communication and Society, 20, 784-799. doi: 10.1080/15205436.2017.1350278

*Strawhun, J., Adams, N., \& Huss, M. T. (2013). The assessment of cyberstalking: An expanded examination including social networking, attachment, jealousy, and anger in retaliation to violence and abuse. Violence and Victims, 28, 715-730. doi: 10.1891/0886-6708.11-00145

*Tandoc, E. C., Ferrucci, P., \& Duffy, M. (2015). Facebook use, envy, and depression among college students: Is Facebook depressing?. Computers in Human Behavior, 43, 139-146. doi: 10.1016/j.chb.2014.10.053

*Taşkiran, H. B. (2019). Uses and gratifications approach, social media and personal branding: A study on social media users in Turkey. Communication Today, 10, 143-155. Retrieved from https://www.communicationtoday.sk/uses-andgratifications-approach-social-media-and-personal-branding-a-study-on-social-media-users-in-turkey/

*Tavani, H. T., \& Grodzinsky, F. S. (2002). Cyberstalking, personal privacy, and moral responsibility. Ethics and Information Technology, 4, 123-132. doi: 10.1023/A:1019927824326

*Temple, J. R., Choi, H. J., Brem, M., Wolford-Clevenger, C., Stuart, G. L., Peskin, M. F., \& Elmquist, J. (2016). The temporal association between traditional and cyber dating abuse among adolescents. Journal of Youth and Adolescence, 45, 340-349. doi: 10.1007/s10964-015-0380-3

*Tian, X. (2016). Network domains in social networking sites: Expectations, meanings, and social capital. Information, Communication \& Society, 19, 188-202. doi: 10.1080/136911 8X.2015.1050051

Tidwell, L. C., \& Walther, J. B. (2002). Computer-mediated communication effects on disclosure, impressions, and interpersonal evaluations: Getting to know one another a bit at a time. Human Communication Research, 28, 317-348. doi: 10.1111/j.1468-2958.2002.tb00811.x

*Tokunaga, R. S. (2011). Social networking site or social surveillance site? Understanding the use of interpersonal electronic surveillance in romantic relationships. Computers in Human Behavior, 27, 705-713. doi: 10.1016/j/chb.2010.08.014

*Tokunaga, R. S. (2016). Interpersonal surveillance over social network sites: Applying a theory of negative relational maintenance and the investment model. Journal of Social and Personal Relationships, 33, 171-190. doi: 10.1177/0265407514568749

*Tokunaga, R. S., \& Aune, K. S. (2017). Cyber-defense: A taxonomy of tactics for managing cyberstalking. Journal of Interpersonal Violence, 32, 1451-1475. doi: 10.1177/08862605 15589564

*Tokunaga, R. S., \& Gustafson, A. (2014). Seeking interpersonal information over the Internet: An application of the theory of motivated information management to Internet use. Journal of Social and Personal Relationships, 31, 1019-1039. doi: $10.1177 / 0265407513516890$ 
Tong, S. T. (2013). Facebook use during relationship termination: Uncertainty reduction and surveillance. Cyberpsychology, Behavior, and Social Networking, 16, 788-793. doi: 10.1089/cyber.2012.0549

Treem, J., \& Leonardi, P. (2013). Social media use in organizations: Exploring the affordances of visibility, editability, persistence, and association. In C. T. Salmon (Ed.), Communication yearbook (vol. 36, pp. 143-189). New York, NY: Routledge.

*Trottier. D. (2012). Interpersonal surveillance on social media. Canadian Journal of Communication, 37, 319-332. Retrieved from http://cjc-online.ca/index.php/journal /article /view/2536/2761

*Trottier. D. (2016). Digital vigilantism as weaponisation of visibility. Philosophy \& Technology, 30, 55-72. doi: 10.1007/s13347-016-0216-4

*Trottier. D. (2018). Scandal mining: Political nobodies and remediated visibility. Media, Culture, \& Society, 40, 893-908. doi: 10.1177/01634437177344008

*Underwood, M. K., \& Ehrenreich, S. E. (2017). The power and the pain of adolescents' digital communication: Cyber victimization and the perils of lurking. American Psychologist, 72, 144-158. doi: 10.1037/a0040429

Van Ouystel, J., Ponnet, K., \& Walrave, M. (2018). Cyber dating abuse victimization among secondary school students from a lifestyle-routine activities theory perspective. Journal of Interpersonal Violence, 33, 2767-2776. doi: 10.1177/0886260516629390

*Vandenbosch, L., \& Eggermont, S. (2016). The interrelated roles of mass media and social media in adolescents' development of an objectified self-concept: A longitudinal study. Communication Research, 43, 1116-1140. doi: 10.1177/0093650215600488

*Vendemia, M. A., High, A. C., \& DeAndrea, D. C. (2017). "Friend" or foe? Why people friend disliked others on Facebook. Communication Research Reports, 34, 29-36. doi: 10.1080/08824096.2016.1227778

*Verduyn, P., Lee, D. S., Park, J., Shablack, H., Orvell, A., Bayer, J., ... \& Kross, E. (2015). Passive Facebook usage undermines affective well-being: Experimental and longitudinal evidence. Journal of Experimental Psychology: General, 144, 480-488. doi: 10.1037/xge0000057

*Verduyn, P., Ybarra, O., Résibois, M., Jonides, J., \& Kross, E. (2017). Do social network sites enhance or undermine subjective well-being? A critical review. Social Issues and Policy Review, 11, 274-302. doi: 10.1111/sipr.12033

*Vinkers, C. D., Finkenauer, C., \& Hawk, S. T. (2011). Why do close partners snoop? Predictors of intrusive behavior in newlywed couples. Personal Relationships, 18, 110-124. doi: 10.1111/j.1475-6811.2010.01314.x

*Wagner, T. R. (2018). When off-line seeks information online: The effect of modality switching and time on attributional confidence and social attraction. Communication Research Reports, 35, 346-355. doi: 10.1080/08824096.2018.1512484

Walther, J. B. (1996). Computer-mediated communication: Impersonal, interpersonal and hyperpersonal interaction. Communication Research, 23, 1-43. doi: 10.1177/009365096023001001

Walther, J. B., \& Parks, M. R. (2002). Cues filtered out, cues filtered in: Computer-mediated communication and relationships. In M. L. Knapp \& J. A. Daly (Eds.), Handbook of interpersonal communication (3rd ed., pp. 529-563). Thousand Oaks, CA: Sage.

*Wang, S. S. (2015). To unfriend or not: exploring factors affecting users in keeping friends on Facebook and the implications on mediated voyeurism. Asian Journal of Communication, 25, 465-485. doi: 10.1080/01292986.2014.990469

*Wang, F., Zeng, D., Hendler, J. A., Zhang, Q., Feng, Z., Gao, Y., ...Lai, G. (2010). A study of the human flesh search engine: Crowd-powered expansion of online knowledge. Computer, 43, 45-53. doi: 10.1109/MC.2010.216

*Wang, K., Zhou, M., \& Zhang, Z. (2017). Can insecurely attached dating couples get compensated on social network sites? - The effect of surveillance. Computers in Human Behavior, 73, 303-310. doi: 10.1016/j.chb.2017.03.046

*Weathers, M. R., \& Hopson, M. C. (2015). "I define what hurts me": A co-cultural theoretical analysis of communication factors related to digital dating abuse. Howard Journal of Communications, 26, 95-113. doi: 10.1080/10646175.2015.988475

Weeks, B., \& Southwell, B. (2010). The symbiosis of news coverage and aggregate online search behavior: Obama, rumors, and presidential politics. Mass Communication \& Society, 13, 341-360. doi: 10.1080/15205430903470532

*Weinstein, E. (2017). Adolescents' differential responses to social media browsing: Exploring causes and consequences for intervention. Computers in Human Behavior, 76, 396-405. doi: 10.1016/j.chb.2017.07.038 
*Weinstein, E. (2018). The social media see-saw: Positive and negative influences on adolescents' affective well-being. New Media \& Society, 20, 3597-3623. doi: 10.1177/1461444818755634

Westerman, D., Van Der Heide, B., Klein, K. A., \& Walther, J. B. (2008). How do people really seek information about others? Information seeking across Internet and traditional communication channels. Journal of Computer-Mediated Communication, 13, 751-767. doi: 10.1111/j.1083-6101.2008.00418.x

*Wise, K., Alhabash, S., \& Park. H. (2010). Emotional responses during social information seeking on Facebook. Cyberpsychology, Behavior, and Social Networking, 13, 555-562. doi: 10.1089/cyber.2009.0365

*Wittkower, D. E. (2016). Lurkers, creepers, and virtuous interactivity: From property rights to consent and care as a conceptual basis for privacy concerns and information ethics. First Monday, 21(10). doi: 10.5210/fm.v21i10.6948

Wood, E., Senn, C. Y., Desmarais, S., Park, L., \& Verberg, N. (2002). Sources of information about dating and their perceived influence on adolescents. Journal of Adolescent Research, 17, 401-417. doi: 10.1177/07458402017004005

Woods, H. S. (2018). Asking more of Siri and Alexa: Feminine persona in service of surveillance capitalism. Critical Studies in Media Communication, 35, 334-349. doi: 10.1080/15295036.2018.1488082

*Wright, M. F. (2015). Cyber aggression within adolescents' romantic relationships: Linkages to parental and partner attachment. Journal of Youth and Adolescence, 44, 37-47. doi: 10.1007/s10964-014-0147-2

*Wright, M. F. (2017). Intimate partner aggression and adult attachment insecurity: The mediation of jealousy and anger. Evolutionary Behavioral Sciences, 11, 187-198. doi: 10.1037/ebs0000097

*Yang, C. (2016). Instagram use, loneliness, and social comparison orientation: Interact and browse on social media, but don't compare. Cyberpsychology, Behavior, and Social Networking, 19, 703-708. doi: 10.1089/cyber.2016.0201

*Yardley, E., Lynes, A. G. T., Wilson, D., \& Kelly, E. (2018). What's the deal with 'websleuthing'? News media representations of amateur detectives in networked spaces. Crime, Media, Culture, 14, 81-109. doi: 10.1177/1741659016674045 


\section{Appendix}

List of Online Social Information Seeking Concepts and Articles that Defined Them (back to text)

Terms

Active (social) information seeking

Adolescent dating violence and abuse

Analytic labor

Computer or mediated privacy invasion

Consumption

Covert surveillance

Creeping

Crowdsourced vigilantism

Cyber monitoring

Cyber or technology privacy invasion

Cyber vigilantism

Cyberstalking

Cybervetting

Digilantism
Articles

Antheunis et al. (2010); Fox and Anderegg (2014); Fox et al. (2013); Gibbs et al. (2011); Ramirez et al. (2002); Ramirez et al. (2016); Stefanone et al. (2013); Wise et al. (2010)

Stonard et al. (2014); Stonard et al. (2017)

Bond et al. (2017); Karakayali and Kilic (2013)

Kennedy-Lightsey and Frisby (2016); Ledbetter et al. (2010)

Burke et al. (2010)

Muise et al. (2014)

Child and Starcher (2016); Fox et al. (2013); Huber and DeGroot (2017); Marcum and Higgins (2019); Muise et al. (2014); Standlee (2019); Trottier (2012)

Chia (2019)

Brem et al. (2019)

Crane et al. (2018); Wright (2017)

Chia (2019)

Adam (2002); Belu et al. (2016); Cavezza and McEwan (2014); Dhillon and Smith (2019); Duerksen and Wooden (2019); Finn (2004); Horsman and Conniss (2015); Huber and DeGroot (2017); Kircaburun et al. (2018); Marcum and Higgins (2019); Marcum et al. (2017, 2018); Marcum et al. (2016); Moriarty and Freiberger (2008); Reyns et al. (2011); Sheridan and Grant (2007); ); Smoker and March (2017); Southworth et al. (2007); Spitzberg and Hoobler (2002); Strawhun et al. (2013); Tavani and Grodzinsky (2002); Tokunaga and Aune (2017)

Ashuri and Bar-Ilan (2017); Berkelaar (2014, 2017a, 2017b); Berkelaar et al. (2016); Berkelaar and Buzzanell (2014, 2015); Berkelaar et al. (2015); Hedenus et al. (2019); Melton et al. (2018); Roth et al. (2019)

Schwarz \& Richey (2019); Yardley et al. (2018) 
Digital dating abuse or cyber dating abuse

Doing homework

Electronic or cyber aggression

Electronic intrusion or electronic intrusiveness

Electronic surveillance

Exotic surveillance

Extractive (social) information seeking

Facebook investigating

Facebook partner-monitoring

Facebook stalking or facestalking

Facebook surveillance

Facebook tracking

Human flesh search

Information seeking

Instagram browsing
Borrajo et al. (2015); Brem et al. (2019); Doucette et al. (2018); Lu et al. (2018); Marcum et al. (2016); Reed et al. (2015); Reed, Tolman, and Ward (2016, 2017); Reed, Tolman, Ward, and Safyer (2016); Temple et al. (2016); Weathers and Hopson (2015)

Standlee (2019)

Bennett et al. (2011); Smith-Darden et al. (2017); Wright (2015, 2017)

Bennett et al. (2011); Doucette et al. (2018); Reed et al. (2015); Reed, Tolman, Ward, and Safyer (2016)

Lopez (2017)

Tokunaga and Aune (2017)

Berkelaar (2017); Gibbs et al. (2011); Ramirez et al. (2002); Ramirez et al. (2016); Stefanone et al. (2013); Wagner (2018); Wise et al. (2010)

Stiff (2019)

Darvell et al. (2011)

Bryant and Marmo (2009); Dreßing et al. (2014); Fox and Tokunaga (2015); Fox et al. (2013); Lewis and West (2009); Lyndon et al. (2011); Marcum and Higgins (2019); Marshall (2012); Marwick (2012); Meenagh (2015); Muise et al. (2014); Samp and Palevitz (2014); Tokunaga (2016); Tokunaga and Aune (2017); Trottier (2012)

Drouin et al. (2014); Marshall (2012); Marshall et al. (2013); Scherr et al. (2018); Stiff (2019)

Stiff (2019)

Chao and Tao (2012); Chang and Poon (2017); Chen and Sharma (2011); Cheong and Gong (2010); Gao (2016); Gao and Stanyer (2014); Ong (2012); Pan (2010); Pantumsinchai (2018); Qiu et al. (2015); Wang et al. (2010)

Ashgar (2015); Ramirez et al. (2002)

Yang (2016) 
Interactive (social) information seeking

Interpersonal electronic surveillance

Interveillance

Intimate partner cyberstalking

Lateral surveillance

Lurking

Mediated lurking

Mediated surveillance

Mediated voyeurism

Monitoring

Monitoring of attractive peers on social networking sites (MAP-SNS)

Online or cyber obsessive relational intrusion

Online (social) information seeking

Online monitoring

Online surveillance
Antheunis et al. (2010); Courtois et al. (2012); Fox and Anderegg (2014); Fox et al. (2013); Fox and Tokunaga (2015); Gibbs et al. (2011); Ramirez et al. (2002); Ramirez et al. (2016); Stefanone et al. (2013); Stewart et al. (2014); Tokunaga and Gustafson (2014); Wise et al. (2010)

Fox and Tokunaga (2015); LeFebvre et al. (2015); Lukacs and QuanHaase (2015); Marcum and Higgins (2019); Marcum et al. (2017, 2018); Marshall (2012); Marshall et al. (2013); Marcum et al. (2017); Muise et al. (2014); Tokunaga (2011, 2016); Vendemia et al. (2017)

Christensen and Jansson (2015); Jansson (2012)

Moor and Anderson (2019); Smoker and March (2017)

Albrechtslund (2008); Andrejevic (2005); Humphreys (2011); Ivana (2013); Lee et al. (2017); Lukacs and Quan-Haase (2015); Pan (2010); Tokunaga (2016); Trottier (2016)

Osatuyi (2015); Park et al. (2012); Pempek et al. (2009); Ramirez et al. (2002); Underwood and Ehrenreich (2017); Wang (2015); Wittkower (2016)

Child and Starcher (2016)

Meenagh (2015)

Bumgarner (2007); Ouwerkerk and Johnson (2016); Wang (2015)

Fuchs (2011); Hellevik (2019); Samp and Palevitz (2014); Seidman et al. (2019); Stewart et al. (2014)

Vandenbosch and Eggermont (2016)

Chaulk and Jones (2011); Marshall (2012); Spitzberg and Hoobler (2002)

Rui et al. (2015); Stefanone et al. (2013); Tokunaga and Gustafson (2014)

Stewart et al. (2014)

Brem et al. (2015); Fulton and Kibby (2017); Tokunaga (2016) 
Parental monitoring

Participatory surveillance

Partner monitoring

Passive consumption of social news

Passive Facebook use

Passive (social) information seeking

Passive usage

Patient-targeted Googling

Post-relationship contact and tracking

Rubbernecking

Scandal mining

Snooping or covert intrusive behavior

Social (media) browsing or profile browsing

Social information consumption

Social information seeking

Social investigation

Social media assessments
Benrazavi et al. (2015); Law et al. (2010); Livingstone and Helsper (2008)

Albrechtslund (2008); Fulton and Kibby (2017)

Muise et al. (2014)

Burke et al. (2011)

Frison and Eggermont (2016); Shaw et al. (2015)

Antheunis et al. (2010); Courtois et al. (2012); Fox and Anderegg (2014); Fox et al. (2013); Gibbs et al. (2011); Ramirez et al. (2002); Ramirez et al. (2016); Stefanone et al. (2013); Stewart et al. (2014); Tokunaga and Gustafson (2014); Wise et al. (2010)

Verduyn et al. (2015); Verduyn et al. (2017)

Ashby et al. (2015); Chester et al. (2017); Clinton et al. (2010); de Arujo Reinert and Kowacs (2019); Eichenberg and Herzberg (2016); Omaggio et al. (2018)

Belu et al. (2016); Lee and O'Sullivan (2014)

Baruh and Cemalcilar (2015); DeGroot (2014)

Trottier (2018)

Derby et al. (2012); Hawk et al. (2015); Rote and Smetana (2018); Vinkers et al. (2011)

Asghar (2015); Baruh and Cemalcilar (2015); Ellison et al. (2011); Ivana (2013); Joinson (2008); Lai (2019); Lampe et al. (2006); Marwick (2012); Metzger et al. (2018); Weinstein (2017, 2018); Wise et al. (2010)

Krasnova et al. (2015)

Burke et al. (2011); Ellison et al. (2011); Rui et al. (2015); Stefanone et al. (2013); Tian (2016)

Joinson (2008); Wise et al. (2010)

Roth et al. (2016) 
Social media surveillance

Social network surfing

Social recruiting

Social searching

Social surveillance

Stalking or checking

Surveillance

Synoptic surveillance

Technology-assisted adolescent dating violence and abuse

Ubiquitous surveillance

Voyeurism

Websleuthing
Fuchs and Trottier (2015); Pearce and Vitak (2016)

Giannakos et al. (2013); Joinson (2008)

El Ouirdi et al. (2016); Root and McKay (2014)

Ashgar (2015); Chaulk and Jones (2011); Ivana (2013); Joinson (2008); Lampe et al. (2006); Marshall et al. (2013); Marwick (2012); McEwan (2013); Quan-Haase and Young (2010); Wise et al. (2010)

Brandtzæg et al. (2010); Marshall et al. (2013); Marwick (2012); Muise et al. (2014); Park et al. (2015, 2019); Scherr et al. (2018); Tokunaga (2011)

Howard et al. (2019); Lewis and West (2009)

Albrechtslund (2008); Botan (1996); Bryant and Marmo (2009); Fuchs (2011); Fuchs and Trottier (2015); Fulton and Kibby (2017); Humphreys (2011); Joinson (2008); Lampe et al. (2006); Lee et al. (2017); Marshall et al. (2013); Marx (2004); Pearce and Vitak (2016); Quan-Haase and Young (2010); Sheldon and Bryant (2016); Tandoc et al. (2015); Taşkıran (2019); Trottier (2012); Vendemia et al. (2017)

Fernback (2013)

Stonard (2019)

Oulasvirta et al. (2014)

Quinn and Papacharissi (2018)

Myles et al. (2018); Yardley et al. (2018) 


\section{Copyrights and Repositories}

\section{(\$) (1)}

This work is licensed under the Creative Commons Attribution-NonCommercial-3.0 Unported License.

This license allows you to download this article, titled "Monitoring, Creeping, or Surveillance? A Synthesis of Online Social Information Seeking Concepts," and share it with others as long as you credit the author and the journal. You cannot use it commercially without the written permission of the author and the journal (Review of Communication Research).

\section{Attribution}

You must attribute the work to the authors and mention the journal with a full citation, whenever a fragment or the full text of this paper is being copied, distributed or made accessible publicly by any means.

\section{Commercial use}

The licensor permits others to copy, distribute, display, and perform the work for non-commercial purposes only, unless you get the written permission of the author and the journal.

The above rules are crucial and bound to the general license agreement that you can read at:

http://creativecommons.org/licenses/by-nc/3.0/

\section{Corresponding author}

Dr. Jessica Frampton at 3016 Derby Hall, 154 N Oval Mall, Columbus, OH 43210;

email: frampton.22@osu.edu

\section{Attached is a list of permanent repositories where you can find the articles published by RCR:}

Academia.edu@http://independent.academia.edu/ReviewofCommunicationResearch

Internet Archive@ http://archive.org (collection "community texts")

Social Science Open Access Repository, SSOAR @ http://www.ssoar.info/en/home.html 